Rhode Island College

Digital Commons @ RIC

\title{
A Case Study of Student and Teacher Relationships and the Effect on Student Learning
}

Patricia Brady Gablinkske

Rhode Island College

Follow this and additional works at: https://digitalcommons.ric.edu/etd

Part of the Educational Assessment, Evaluation, and Research Commons

\section{Recommended Citation}

Gablinkske, Patricia Brady, "A Case Study of Student and Teacher Relationships and the Effect on Student Learning" (2014). Master's Theses, Dissertations, Graduate Research and Major Papers Overview. 106. https://digitalcommons.ric.edu/etd/106

This Dissertation is brought to you for free and open access by the Master's Theses, Dissertations, Graduate Research and Major Papers at Digital Commons @ RIC. It has been accepted for inclusion in Master's Theses, Dissertations, Graduate Research and Major Papers Overview by an authorized administrator of Digital Commons @ RIC. For more information, please contact digitalcommons@ric.edu. 
A CASE STUDY OF STUDENT AND TEACHER RELATIONSHIPS

AND THE EFFECT ON STUDENT LEARNING

BY

PATRICIA BRADY GABLINSKE

A DISSERTATION SUBMITTED IN PARTIAL FULFILLMENT OF THE

REQUIREMENTS FOR THE DEGREE OF

DOCTOR OF PHILOSOPHY

IN EDUCATION

RHODE ISLAND COLLEGE

AND

UNIVERSITY OF RHODE ISLAND

2014 


\section{DOCTOR OF PHILOSOPHY DISSERTATION $\mathrm{OF}$ PATRICIA BRADY GABLINSKE}

APPROVED:

Dissertation Committee:

Major Professor Patricia Cordeiro

Peter Adamy

James Barton

David Byrd

Dean Nasser H. Zawia

UNIVERSITY OF RHODE ISLAND

2014 


\begin{abstract}
This research study explored the affective domain of teacherstudent relationships using a single case study design. This single case study produced a synthesis of information that guides a classroom teacher in the development and maintenance of her relationships with her students. The resulting analysis and interpretation provided a description of major themes that developed regarding strong teacher student relationships, as well as, specific components to the interactions considered essential for the student's learning environment.
\end{abstract}

The outcome of this study is an account of experiences and procedures that guide the development and maintenance of relationships between a teacher and her students. Based on the findings, four primary categories emerged with supporting elements that were critical components of each category. These four primary categories represent an interpersonal framework for the learning environment.

The qualitative method in this study is derived from a constructivist viewpoint with a focus on deeply understanding this specific case of teacher-student relationships. My goal in conducting this study was to provide more specific examples of and empirical findings for how 
teacher-student relationships are created. Identifying specific factors associated with teacher-student interactions could provide valuable information to an educational learning community. Implications for how these findings can impact the learning environment are discussed. 


\section{ACKNOWLEDGEMENTS}

Many people have been invaluable to me as I journeyed on this road to dissertation; however, my deepest gratitude goes to my major professor, Dr. Patricia Cordeiro. Her support and encouragement has been the wind beneath my wings. She has been unwavering in her belief that I could do this and do it well. With her guidance and thoughtful insight, I have fulfilled a lifelong dream.

I would like to express my deep appreciation to my committee members, Dr. David Byrd, Dr. Jim Barton, and Dr. Pete Adamy for all their guidance and steadfast support throughout this doctoral process. They, too, have been invaluable to me.

I also want to thank my research participant for all the time and effort she put into this study. Her willingness to share her practices and her insight is greatly appreciated. Her participation will make an important contribution to the field of education.

I extend a special thank you to the members of my Cohort of 2007, in particular, Mary Jo LaRocco, for her unwavering support and prayers. 
I have made lasting friendships on this doctoral journey which I will always cherish.

To my husband, Doug, eternal love for encouraging me to fulfill this lifetime dream of getting my doctorate; and to Lauren and Derek, the other two greatest accomplishments of my life, all my love. 


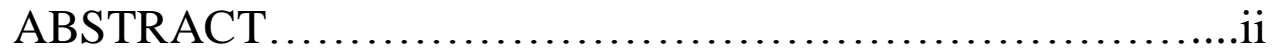

ACKNOWLEDGEMENTS...............................iv

TABLE OF CONTENTS ...................................vi

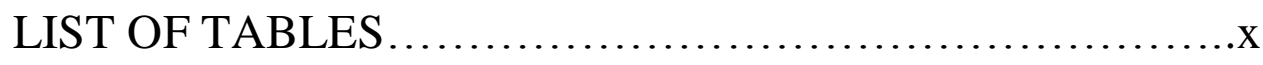

LIST OF FIGURES ...................................

CHAPTER 1: INTRODUCTION ............................

Statement of the Problem...............................1

My Connection to the Study ........................... 3

Purpose of the Study $\ldots \ldots \ldots \ldots \ldots \ldots \ldots \ldots \ldots \ldots \ldots \ldots . \ldots 4$

Significance of the Study ............................ 5

Definition of Key Terms ............................ 8

Summary and Outline of the Study.....................10

CHAPTER 2: REVIEW OF LITERATURE ..................12

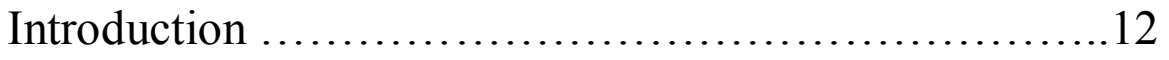

Constructivist Framework ...........................16

Historical Context ................................ 18

Perspectives of Teacher-Student Relationships ............21 


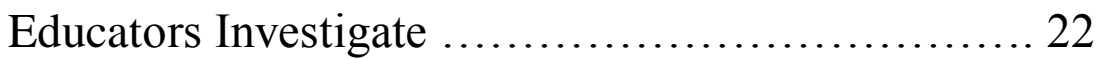

Psychologists Investigate $. . \ldots \ldots \ldots \ldots \ldots \ldots \ldots \ldots \ldots . \ldots \ldots$

Sociologists Investigate $\ldots \ldots \ldots \ldots \ldots \ldots \ldots \ldots \ldots \ldots \ldots \ldots$

Student Perspectives .............................. 32

Instructional Implications $\ldots \ldots \ldots \ldots \ldots \ldots \ldots \ldots \ldots \ldots \ldots \ldots \ldots$

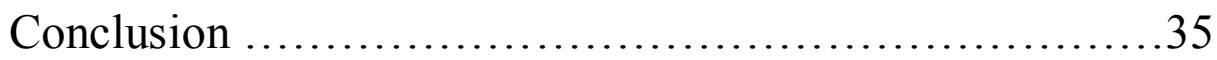

\section{CHAPTER 3: METHOD}

Research Design .........................................37

Theoretical Framework ....................................38

Social Constructivist ............................. 38

Setting for the Study $\ldots \ldots \ldots \ldots \ldots \ldots \ldots \ldots \ldots \ldots \ldots \ldots \ldots . \ldots \ldots 2$

Sampling Design ......................................43

General Characteristics of the Participants ................. 44

Statement on Researcher as Instrument ....................45

Data Collection: Sources and Procedure ...................49

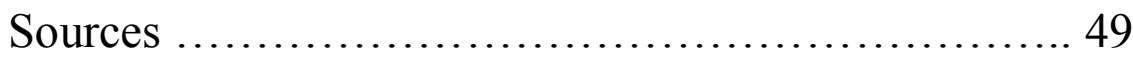

Procedure .......................................... 51

Data Analysis .......................................... .52

Interview Guide ...................................... 53 
Terms of Validity and Reliability ..........................54

Ethical Issues ...........................................56

Resources Required ................................ 57

CHAPTER 4: FINDINGS ....................................58

Interview and Observation ..............................59

Analysis of Findings....................................60

Research Questions .................................. 75

Presentation of Results ............................... 78

Contextual Category 1: Classroom Climate ............78

Contextual Category 2: Classroom Layout with

Purposeful Design .............................81

Contextual Category 3: Teacher Interaction Behaviors .85

Contextual Category 4: Delivering Instruction .........88

Research Question 2 ...............................92

Conclusion.............................................96

CHAPTER 5: CONCLUSION .................................97

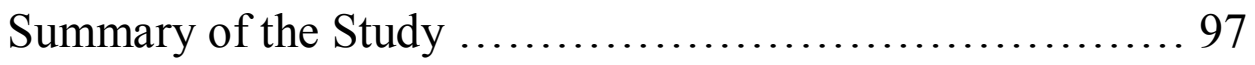

Interpretation and Implications of the Study ...............99

viii 
Finding: Contextual Category 1 .....................101

Finding: Contextual Category 2 ................... 102

Finding: Contextual Category 3 ....................102

Finding: Contextual Category 4 ....................105

Findings for Research Question 2 ................ 107

Summary ........................................ 109

Implications for the Field of Education .................... 110

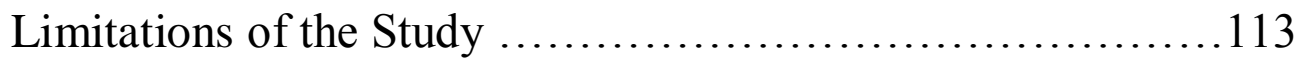

Suggestions for Future Research ....................... 115

Conclusion........................................... 117

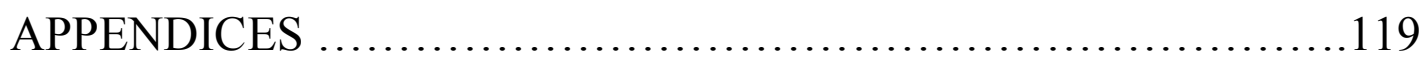

Appendix A: Marzano Observation Protocol ..................119

Appendix B: Observation Protocol .........................121

Appendix C: Interview Protocol ..........................122

Appendix D: Participant Informed Consent ..................123

Appendix E: District Consent Form .....................125

Appendix F: Statement of Purpose Document ................127

Appendix G: TESA Interaction Protocol .....................129

BIBLIOGRAPHY ........................................... 131 


\section{LIST OF TABLES}

\section{TABLE}

Table 1. Sample of Transcript Statements coded using Marzano Protocol

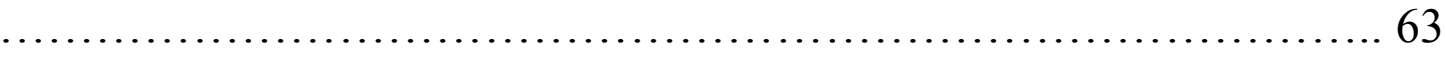

Table 2. TESA Interaction Model .................................... 69

Table 3. Intervention and observation codes using TESA interaction

model......................................................... 71 


\section{LIST OF FIGURES}

FIGURE

PAGE

Figure 1. Data analysis steps for contextual categories......... 77 


\section{INTRODUCTION}

\section{Statement of the Problem}

Race to the Top (RttT) initiatives have strongly focused on measuring teacher effectiveness primarily using standardized test scores. However, there is a large body of research that examines the value of a teacher's affective acumen when it comes to a teacher's effectiveness as an educator (Brophy, 1974; Baker, 1999; Crosnoe, Johnson, \& Elder, 2004; Grant \& Rothenberg, 1986; Hamre, Pianta, Burchinal, Field, Crouch, Downer, Howes, LaParo, Little, 2012; Leder, 1987). An approach to accountability that includes a broader range of measurement of effective classroom instructional practices should include the relationships the teacher builds with her/his students. Marzano (2003) studied the practices of effective teachers and determined that "an effective teacher-student relationship may be the keystone that allows the other aspects to work well” (p. 91).

The relationships that teachers develop with their students have an important role in a student's academic growth. Hallinan (2008) writes "Learning is a process that involves cognitive and social psychological dimensions, and both processes should be considered if academic achievement is to be maximized" (p. 271). 
The unbalanced reliance on test scores to determine success does not provide an accurate accounting of all that goes into creating an effective learning environment. Rothstein, Jacobsen, \& Wilder (2008) agreed saying, "it is surprising that so many education policymakers have been seduced into thinking that simple quantitative measures like test scores can be used to hold schools accountable for achieving complex educational outcomes" (p. 27).

Meyer \& Turner (2002) discussed their findings illustrating the importance of students' and teachers' emotions during instructional interactions. They determined that "through studying student-teacher interactions, our conceptualization of what constitutes motivation to learn increasingly has involved emotions as essential to learning and teaching" (p.107). Their results provide support for further study of the inclusion of interpersonal relationships in the instructional setting and to what degree those relationships affect the students' learning environment. The quality of the relationship between a student and the teacher will result in a greater degree of learning in the classroom according to Downey (2008).

Mohrman, Tenkasi, \& Mohrman, (2003) assert "lasting change does not result from plans, blueprints, and events, rather change occurs 
through interaction of participants" (p. 321). Strong teacher-student relationships may be one of the most important environmental factors in changing a child's educational path (Baker, 2006). This case study will explore the environmental factors that are deliberately created by the study participant as she interacts with the student on their educational path. As Cazden (2001) asserts, the establishment of social relationships can seriously impact effective teaching and accurate evaluation in a classroom.

\section{My Connection to this Study}

My role in this case study is shaped by my previous experience working in the field of elementary education for the last twenty years, seven of those years as a building administrator in three different districts with diverse student populations. My teaching experience as a special educator afforded me the opportunity to be embedded in a variety of classrooms, working alongside teachers in grades kindergarten through five, providing student support. I believe these experiences have given me unique insight, understanding, and knowledge of teaching and learning. I also know that these experiences have shaped certain biases, although every effort will be made on my part to remain neutral as a 
qualitative researcher and let the data shape my analysis and interpretation.

\section{Purpose of the Study and Research Question}

Many in the field of education recognize the importance of the relationships that teachers develop with their students that result in positive academic outcomes. My purpose is to conduct a case study of the strategies used in one information-rich classroom that demonstrates teacher-student interactions in an authentic instructional environment. Responsive interviewing procedures will allow this researcher to identify the thought process of the teacher as she is developing student relationships and delivering instruction. Downey (2008) writes that "teachers need to know how their daily work in classrooms can be infused with interactions and instructional strategies that research has shown can make a positive difference in the lives of students who are at risk of academic failure" (p.56).

This qualitative study addressed the following research questions: How does this teacher describe her process for building relationships with her students? What specific components of the teacher/student interactions are essential to a learning environment? 
The results of this study are practical in nature and will include a commonality of affective characteristics and strategies employed by a teacher that influences the students' learning environment and learning experience.

\section{Significance of the Study}

A good deal of literature provides evidence that strong relationships between students and their teachers are essential to the development of all students in school (Hamre \& Pianta, 2006; Birch \& Ladd, 1998). Hamre \& Pianta report that positive student-teacher relationships are a valuable resource for students. They suggest that having a positive relationship with a teacher allows students to be able to work on their own because they know they can count on their teacher if problems arise - that the teacher will recognize and respond to the problem. As children enter formal school settings, relationships with teachers provide the foundation for successful adjustment to the social and academic environment (p. 49).

Hamre \& Pianta recommend that "talking with a teacher and conducting observations in the classroom will provide important and unique information for designing interventions" (p. 55). These researchers conclude that "forming strong and supportive relationships with teachers allows students to feel safer and more secure in the school 
setting, feel more competent, make more positive connections with peers, and make greater academic gains" (p. 57).

Although research is growing in this area, more empirical evidence is needed on aspects of student-teacher relationships in order to better effectively integrate this skill into existing teacher programs (Hamre \& Pianta, 2006; Sarason, 1999; Crosnoe, Johnson, \& Elder (2004).

Research on factors related to quality in classrooms suggests that teachers' attitudes and beliefs about children are very important components to predicting the quality of a child's education (Pianta, LaParo, Payne, Cox, \& Bradley, 2002). A teacher's personal interactions with his or her students can make a significant difference for students. The importance of teachers' relationships with their students cannot be overstated according to Downey (2008). As Darling-Hammond (2006) explains it, "teaching is in the service of students, which creates the expectation that teachers will be able to come to understand how students learn and what students need if they are to learn effectively - and that they will incorporate that into their teaching" (p. 4). It is this idea of determining what needs to be incorporated into instruction for effective learning that I would like to investigate using an authentic learning environment through an illuminative case study. 
The current research base focuses broadly on teacher-student relationships. This study will describe purposeful affective strategies and interactions with students that a teacher uses to effectively engage students in the learning process. This study will contribute to the field of education by providing teachers and administrators with guidance on relationship-building strategies that a highly effective teacher utilizes in a real world, authentic setting - the classroom. After completing an ecological study on teacher-child relationships and behavior problems, O'Connor, Dearing, \& Collins (2011) write that in regard to teacher education, their study demonstrates "the importance of fostering elementary school teachers' awareness of the role of their relationship with students, and provides teachers with information as to how to support high quality relationships with their students" (p. 152).

As Darling-Hammond (2006) believes, "it is up to the educators to instruct policy makers and the public about what it takes to teach effectively in today's world" (p. 3). She feels educators have little input in helping to create the kinds of learning environments that allow teachers to practice well and allow children to learn and succeed (Darling Hammond, 2006). What we can learn through this case study is an attempt to 
reclaim a voice in shaping quality teaching practices that children thrive in.

The concept of teachers building relationships with their students in order to be seen as a credible and trustworthy source of information is a worthwhile endeavor for long term learning (McCombs \& Whisler, 1997; Wubbels \& Brekelmans, 2005; Langer, 1997). For the purpose of this study I will focus on actual practices and deliberate steps a teacher takes to build relationships with her students in order to effectively deliver the instruction necessary for learning.

\section{Definition of Key Terms}

Explication is the process of defining terms and operations in a qualitative research study and serves as a strategy for dealing with bias. Taking care to define terms and operations affords the researcher and reader clarity by making some important components of the study more explicit (Stake, 2010).

The following is a list of terms that will be used in this research study:

1) Verstehen: The German word for personal understanding. Qualitative researchers reach many of their interpretations through experiential understanding - understanding from their own personal experience or 
from the recollections and artifacts of the personal experience of others (Stake, 2010).

2) Zone of Proximal Development: The distance between the actual developmental level of the child by independent problem solving and the level of potential development as determined through problem solving under adult guidance (Vygotsky, p. 86).

3) Social constructivism: knowledge is socially constructed where individuals create meaningful learning through interactions with others.

4) Illuminative Cases: an example of an excellent program to learn under what conditions the program exemplifies excellence.

5) Responsive Interviewing Model: an approach to depth interviewing research which relies heavily on the interpretive constructionist philosophy mixed with a bit of critical theory; the goal being to generate a depth of understanding rather than breadth (Rubin \& Rubin, 2005).

6) Lab Teacher: A classroom teacher they trained and mentored in best practices in a variety of content areas who open their classrooms for observation purposes so other teachers in the field of education (inside 
and outside the district) can come to acquire new instruction and content knowledge.

7) Educational Resilience: a dynamic set of interactions between the student and the educational environment that work together to interrupt a negative trajectory and support academic success (Downey, 2008).

\section{Summary and Outline of the Study}

In Chapter One, I provide an introduction and overview of the framework of this study and my role in conducting this study. I also introduce the research problem addressed in this study, the purpose and significance of the study in relation to previous research, and my specific research questions. The chapter concludes with key terms and definitions that are used in the following chapters.

In Chapter Two, I review the literature relevant to this study. The literature review includes an historical context of the importance of teacher-student relationships, as well as, a diverse range of perspectives on this topic organized by categories of researchers.

Chapter Three is an account of the research design used in this study, including the methods used for data collection and data analysis. 
Chapter Four contains the findings of this study; and in Chapter Five I discuss the implications of these findings and their relevance in the field of education. 


\section{CHAPTER 2}

\section{REVIEW OF THE LITERATURE}

This chapter will provide a review of the literature on the topic of building strong interpersonal relationships with students and the effect that has on the learning environment. The perspectives of a variety of disciplines will be discussed from an historical viewpoint to current thinking on this topic.

\section{Introduction}

There is a great deal of literature that provides substantial evidence that strong relationships between teachers and students are essential components to the healthy academic development of all students in schools (Birch \& Ladd, 1998; Hamre \& Pianta, 2001; Pianta, 1999; Eccles \& Wigfield, 2002). This body of literature involves several genres of research that have been conducted over the past three decades investigating the interactions between teachers and their students and what effect those interactions have on learning. There is credible evidence that the nature and quality of teachers' interactions with children has a significant effect on their learning (Brophy-Herb, Lee, Nievar, \& Stollak, 2007; Curby, 
LoCasale-Crouch, Konold, Pianta, Howes, Burchinal, ... Oscar 2009; Dickinson \& Brady, 2006; Guo, Piasta, Justice, \& Kaderavek, 2010; Howes, Burchinal, Pianta, Bryant, Early, Clifford, \& Oscar, 2008; Jackson, Larzelere, St. Clair, Corr, Fichter, \& Egertson , 2006; Mashburn, Pianta, Hamre, Downer, Barbarin, Bryant, ... Howes, 2008; McCartney, Dearing, Taylor, \& Bub, 2007; Pianta, Barnett, Burchinal, \& Thornburg, 2009). Educators, psychologists, social constructivists, and sociologists have all contributed to the growing interest in targeting interventions toward improvements in the quality of teachers' interactions with children. Hamre, Pianta, Burchinal, Field, Crouch, Downer, Howes, LaParo, \& Little, (2012) posit that "teachers need to be actively engaged in interactions with children in order for learning to occur" (p. 98).

However, in 2001 President Bush signed into law the No Child Left Behind Act (NCLB) that began the intense focus on standardized testing as the measure of, not only student success, but teacher performance as well. It mandated that every child would perform at grade level and achieve high academic standards (U.S. Department of Education, 2007). NCLB was intended as a means 
of supervision for public schools in the United States with the guarantee of success for all students regardless of race, gender, or ability. High stakes testing is the vehicle through which student achievement is measured according to NCLB and does not take into account any other means for measuring student or teacher success.

As a result, the current educational climate emphasizes school accountability through standardized test scores as the primary method for determining an effective learning environment. Federal, state, and local educational policy requires that schools and classrooms should be held more responsible for the outcomes they produce (e.g., student achievement). However, the process for ensuring accountability rests on standardized testing of children, typically starting in third grade (La Paro, Pianta, \& Stuhlman, 2004). The focus on accountability and standardized testing should not confuse the contribution that the social quality of teacher student relationships has on academic development (Hamre \& Pianta, 2006). Hamre \& Pianta contend that strong student- teacher relationships "provide a unique entry point for educators working to improve the social and learning environments of schools and classrooms" (p. 49). 
I, too, believe there is an important role that the quality of teacher and student interactions plays regarding student learning. Hamre et al. (2012) hypothesized that "it was not sufficient for teachers to be able to gain knowledge about effective teacher-child interactions; they needed actual skills involving identification of effective interactions with a high degree of specificity in order to be most likely to transfer the coursework into changes in their practice" (p. 98).

While researching the effects teachers have on student learning, Good, Biddle, \& Brophy (1976) determined that teachers do make a difference. A large contribution to what brought about that difference was the affective component to teaching that the teachers used. Good et al. found that students who held a sense of futility toward school had the worst achievement record. These students needed teachers who believed in them and were willing to work with them. Good et al. cite several studies by Aspy (1973) that demonstrate the importance of teachers' affective behavior. What Good et al. found was that teachers who showed an interest in their students by indicating they were listening to them and understood students' need completely and accurately, had students who obtained 
higher scores on a standardized test of learning -- "the evidence was impressive" (p. 371). The following review of the literature will further reveal impressive evidence of the effect that teacher-student relationships have on a child's learning environment.

\section{Constructivist Framework}

Constructivism is a theory of learning. As such, a constructivist approach to learning sees the learning environment as a "mini-society, a community of learners engaged in activity, discourse, interpretation, justification, and reflection" (Fosnot, 2005; p. ix). While constructivist theory of education indicates that knowledge is constructed individually by the student, that learning occurs in a social environment (classroom) with experiences that have been carefully constructed by the teacher. In biological theorists' terms, there is "an active interplay of the surround (environment) to evolution and to learning" (p. 11). The constructivist teacher encourages a consideration of others' points of views and a mutual respect, allowing the development of independent and creative thinking. From a constructivist perspective, meaning is understood to be the result of individuals (in this case, teachers) "setting up relationships, reflecting 
on their actions, and modeling and constructing explanations" (Fosnot, p. 280).

Contemporary theorists and researchers' beliefs have shifted from isolated student mastery of concepts to ideas that real learning is about interaction, growth, and development (Fosnot, 2005). New information from the realm of cognitive science tells us that students learn through progressive structuring and restructuring of knowledge experience, "that deep conceptual learning is about structural shifts in cognition; without exchange with the environment, entropy would result" (p. 279). That knowledge is actively constructed is a pervasive tenet of constructivist thinking. The way a teacher listens and talks to children helps them become learners who think critically and deeply about what they read and write (Fosnot, p. 102). By frequently engaging with the student collaboratively, a teacher increases his/her understanding of how a particular learner acquires knowledge and therefore becomes responsive to the learner's needs.

Constructivist theorists DeVries \& Zan (2005) write "the preoccupation in most schools with subject matter content has led to a situation in which affective development is negatively influenced" ( $p$. 132). Ironically, they say this one-sided preoccupation has created a 
situation in which intellectual development does not flourish either they contend that "in order to foster intellectual development, a certain kind of interpersonal framework must be created" (p. 133). It is their opinion that a primary focus of a constructivist education is the development of a network of interpersonal relations that will dominate the child's school experience. They contend "interpersonal relations are the context for the child's construction of the self, of others, and of subject-matter knowledge" (p. 132).

Bruner (1977) writes that the process of education requires that "schools must also contribute to the social and emotional development of the child if they are to fulfill their function of education" (p. 9). Bruner develops four themes he considers essential to the process of learning - one of them relates to stimulating the desire to learn, creating interest in the subject being taught, and what he terms "intellectual excitement" (p. 11). He suggests studying the methods used by 'successful' teachers as a way of determining effective practices (p. 30). Constructivism provides a natural and best frame for this study because a major tenet of a constructivist researcher is to look at the processes of interaction among individuals in the context of where they live and work. 


\section{Historical Context}

In 1840, Mann said "the aptness to teach involves the power of perceiving how far a scholar understands the subject matter to be learned and what, in the natural order is the next step to take" (p.16). According to him, the teacher must be intuitive and lead the minds of his pupils to discover what they need to know and then supply them with what they require (p.17).

Dewey (1938) said that as an educator, you need to be able to discern what attitudes are conducive to continued growth and what are detrimental, and use that relational knowledge to build worthwhile educational experiences for students. He writes that "teachers are the agents through which knowledge and skills are communicated and rules of conduct enforced" (p.18) and, as such, it is the duty of the teacher to know how to "utilize the surroundings, physical and social, so as to extract from them all that they have to contribute" to building up worthwhile educational experiences (p.40). He says that "all human experience is ultimately social: that it involves contact and communication" (p. 38).

Dewey believed the goal of educators is to create lifelong learners. This is accomplished through the knowledge the educator 
has of individuals that leads to social organizations providing all students with the opportunity to contribute to something (p. 56). Dewey says: "The principle that development of experience comes about through interaction means that education is essentially a social process" (p. 58).

Vygotsky (1978) believed that higher mental functionings are socially formed and culturally transmitted. Cognitive development is mediated through language dialogues between one who knows (teacher) and one who is learning (student). Vygotsky posits that the instructional message gradually moves from teacher-student dialogue to inner speech where it organizes the student's thought and becomes an internal mental function. A skillful teacher could shape a student's thinking process through purposeful interaction - Vygotsky's concept of mediated development. According to Vygotsky, "learning awakens a variety of internal development processes that are able to operate only when a child is interacting with people in his environment and in cooperation with his peers" (p. 90). Vygotsky viewed tests as an inadequate measurement of a child's learning capability; he thought the progress in concept formation achieved by a child through interaction with an adult was a much more viable way to determine 
the capabilities of learners. His theory of the zone of proximal development required this type of interaction between child and adult in order for the child to come to terms with and understand the logic of adult reasoning in order to learn new concepts. Vygotsky describes the zone of proximal development as "the distance between the actual developmental level and the level of potential development as determined through problem solving under adult guidance" (p. 86).

In his seminal study, Jackson (1968) studied life in classrooms and determined that "there is a social intimacy in schools that is unmatched elsewhere in our society" (p. 11). According to Jackson, the teacher is charged with managing the flow of the classroom dialogue. In elementary classrooms, he writes, "teachers can engage in as many as one thousand interpersonal exchanges a day" (p. 11). That being the case, the study of those interpersonal exchanges could yield important information regarding the learning that results from those interactions.

\section{Perspectives on Teacher-Student Relationships}

There is a diverse range of perspectives in the area of interactions between teachers and students that have been researched over the past few decades; however, they share several core 
principles. What follows in this literature review is a sampling of those perspectives as they relate to the effect teacher-student interactions has on the learning environment including findings and implications, organized by categories of researchers.

Educators Investigate: "What do positive teacher-student relationships look like in the classroom?"

Downey (2008) conducted a study synthesizing educational research on factors that affect academic success. The rationale for the study was to examine classroom practices that made a difference for all students, but in particular, for students at risk for academic failure. What was determined was that a teacher's personal interaction with his/her students made a significant difference.

The recommendations from Downey's analysis were that "students need teachers to build strong interpersonal relationships with them, focusing on strengths of the students while maintaining high and realistic expectations for success" (p. 57). These interactive relationships should be based on respect, trust, caring, and cohesiveness. A sense of belonging is another important 
byproduct of a strong teacher-student relationship that is critical to a student's success in school. Downey concludes by saying "the study served as a powerful reminder that everyday teacher-student interactions in the classroom matter" (p. 63).

Ravitch (2010) writes that "the goal of education is not to produce higher test scores, but to educate children to become responsible people with well-developed minds and good character" (p. 227). She says that "accountability as it is now is not helping our schools because its measures are too narrow and imprecise, and its consequences too severe. NCLB assumes that accountability based solely on test scores will reform American education. This is a mistake" (p.163). Overemphasis on test scores to the omission of other important goals of education may actually weaken the love of learning and the desire to acquire knowledge (Ravitch, 2010). The significance of the affective domain in determining effective teachers and teaching practices is a component that the current teacher evaluation system does not give enough credence to. Student learning outcomes (measured by test scores) are considered, overwhelmingly, to be the deciding determinant of a highly effective teacher and a highly effective school. 
Langer (1997) writes "if the source of information is someone we respect, we are more likely to be influenced and retain the information than if we view the source as untrustworthy" (p. 86). Initial gathering of information relies on the source of the information. "When we have learned information mindfully, we remain open to ways in which information may differ in various situations" (p. 87). In effect, by building solid relationships with students, teachers are creating discriminating, as well as lifelong learners. Although, over time, the source of the information may be forgotten, the information received is retained (Langer, 1997).

Cazden (2001) states that “children's intellectual functioning, at school, as at home, is intimately related to the social relationships in which it becomes embedded. Familiarity facilitates responsiveness which plays an important part in learning" (p.17). Cazden believes in the importance of creating a learning environment that incorporates building an affective interpersonal relationship with students. Creating a learning environment that all the stakeholders are invested in will have a positive impact on the learning that will take place. As Cazden writes, "What counts are relationships between the teacher and each student, as an individual, both in whole class lessons and in 
individual seat work assignments. Now each student becomes a significant part of the official learning environment" (p. 131).

Marzano (2003) suggests a useful question for anyone wishing to understand factors that improve student achievement is to ask "What influence does an individual teacher have on a student apart from what the school does?" (p. 71). He indicates that all researchers agree that the impact of decisions made by an individual teacher is far greater than the impact of decisions made at the school level. Marzano writes "the core of effective teacher-student relationships is a healthy balance between dominance and cooperation" (p.49). Showing interest in students as individuals has a positive impact on their learning according to Marzano. McCombs \& Whisler (1997) posit that the need for the teacher to show a personal interest in their students is vital to their learning.

All agree that the interaction between teacher and student has a significant impact on student learning in the classroom.

Psychologists Investigate: “What do good teacher-student relationships look like and why do these relationships matter?" 
"What effect does a positive relationship with teachers have on a student?”

Sarason (1999) looks at teaching as a performing art, and discusses the "art of teaching" and the role that teacher interaction plays in creating a "productive learning" environment. He posits that, post - World War II, when training teachers, education has increasingly focused on subject matter to the detriment of pedagogy - "the obligation of the teacher to know who the learner is and make the subject matter interesting, motivating, and compelling for their students" (p. 97). He asks "are there not characteristics of a good teacher which can be observed in which the teacher interacts with children?" (p. 102). Such a candidate would be someone capable of understanding, motivating, and guiding the intellectual, as well as the social-personal development of children. Sarason contends "If you do not know the minds and hearts of learners, you subvert productive learning" (p. 110) - that this is the starting point of all learning.

Sarason contends that there are three overarching features for productive learning; the first is recognizing and respecting the individuality of the learner. The second is for the teacher to know 
the subject matter sufficiently to be able to determine when the learner may have difficulty and be able to intercede to prevent the difficulty from happening. The third tenet is that the teacher is constantly looking for ways to engage and stimulate the learner so he/she wants to learn. By building relationships with students, teachers can fulfill what Sarason contends is the overarching purpose of schooling - motivate learners to experience personal and cognitive growth. It is Sarason's position that not having a system in place that assesses how teachers interact with children is a major problem in the field of education, one that will continue to short change future generations of students and teachers (p. 113). Teachers need to establish a relationship with their students which engender trust, respect, and an understanding of them as learners. He considers it an essential component to teaching and learning he asks that teachers be "both accomplished performers and astute psychologist" (p. 67).

Eccles \& Wigfield (2002) investigated motivational beliefs and values that guide a student's learning process. They define motivation as the study of action; in particular, they focus on achievement motivation. They posit that people have expectations 
about success as well as values and reasons for doing an activity. There is an expectation for success and a sense of control over outcomes that are related beliefs that motivate individuals when completing tasks - especially challenging tasks. This sense of selfefficacy is strong in some people but weak in others.

As reported by Eccles and Wigfield, "not knowing the cause of one's successes and failures undermines one's motivation to work on associated tasks" (p. 111). They determine that having a strong sense of control and confidence over your outcomes leads to success. Eccles and Wigfield refer to a 1998 study by Skinner, Zimmer-Gembeck, \& Connell where the development of students' beliefs was charted over a number of school years. They compared the children's perceived control to the perception children had of how the teachers treated them. He determined that "children who believed teachers were warm and supportive developed a more positive sense of their own control over outcomes" (p.112).

Hamre and Pianta (2006) also investigated the importance of teacher - student relationships. They posit that positive relationships between teacher and student serve as a resource to students as it helps maintain their engagement in academic pursuits. 
This extended engagement leads to better grades. Hamre \& Pianta cite a study by Gregory \& Weinstein (2004) that indicated that student-perceived teacher connection was the factor most closely associated with growth in achievement from $8^{\text {th }}$ to $12^{\text {th }}$ grade (p. 50). For younger children, Birch \& Ladd (1998) concluded that kindergarten children who did not have a good relationship with their teacher exhibited less classroom participation and achievement. These negative relationships continued to affect the quality of the students' relationships in first and second grade (Pianta \& Hamre, 2006). Poor teacher-student relationships were considered a predictor of "sustained academic problems" and an indicator of future school difficulties (p. 52). These findings indicated the importance of teachers building solid relationships as they have a direct impact on academic achievement for years to come.

Hamre \& Pianta (2006) suggest that schools actively encourage staff members to engage with their students and learn about students' outside interests so staff can connect with them on a more personal level. Hamre \& Pianta's contention is that a strong teacher-student relationship is essential for success in school and 
because of this, "ways to build good solid teacher- student relationships should be explicitly targeted in school intervention plans" (p. 56). These strong and supportive relationships allow students to feel competent to make greater academic gains.

Hamre \& Pianta (2006) acknowledge the growing research that supports the efficacy of building teacher-student relationships and recommend that more empirical evidence is needed to develop how to go to scale with efforts targeting student-teacher relationships and how to sustain these efforts over time. Their position is that this will ultimately help make schools more responsive to the diverse learning needs in classrooms.

Sociologists Investigate: "What is the contribution that social aspects of school make to a child's education?"

Crosnoe, Johnson, \& Elder (2004) researched the effect 'alienation' of youths from the school community had on their academic and behavioral performance in school. Alienation is defined as feelings of disconnectedness from others. They contend that "students' alienation contributes to academic problems which lead to problems on a societal level" (p. 60). They stress the need 
to consider more social aspects of schooling such as the relationship that teachers build with their students. They studied whether an affective dimension of teacher-student relationships predicts academic progress and behavior problems. In a longitudinal study of adolescents in grades $7-12$ it was revealed that positive teacher-student relationships were associated with better student outcomes both academically and behaviorally. Crosnoe et al. concluded that "students who had more positive views of their teachers did better and had fewer problems in school" (p. 75). Their recommendation, based on these conclusions, is that research should delve more deeply into teacherstudent relationships; in particular, exploring the connection between the affective dimensions of these relationships. They consider good student-teacher relationships to be a resource to schools and the students and should be promoted as such. Facilitating interpersonal relations, from a sociological viewpoint, is important to keeping students committed to the educational process. 
Student Perspectives: "How do students perceive their relationships with teachers? What effect does that perception have on their learning?"

Baker (1999) conducted a study of "at risk students." These at risk students were defined as students designated as having a high probability of poor developmental or school outcomes. Baker reports that at risk students often report feeling alienated and disenfranchised from the culture of school. When asked, students reported that they were satisfied with school if they perceived their relationship with their teacher as a caring and supportive one.

The current emphasis on instructional methodology and curriculum has usurped the importance of the relationship teachers create with their students. Baker (1999) posits that because elementary students spend such significant amounts of time with one teacher, the opportunity to build relationships between students and teachers is enhanced at this level.

Baker surmises that students who have dropped out of school "seem not to have the social connectedness with adults at school that could function as a protective factor in the face of academic or 
life stressors" (p. 59). She concludes that students' interactions with teachers and the quality of the interactions are potential influences on school performance.

Although Baker's study focused on students who were "at risk" for failure or behavior problems, her findings could also transfer to the school performance of any student.

Brekelmans \& Wubbels, (2005) also conducted a study that showed that students' perceptions of teacher influence were related to cognitive outcomes. The higher a teacher was perceived on the influence dimension, (an interpersonal perception profile), the higher the outcomes of students on a physics test. In their study, teacher influence was the most important variable at the class level. They report that the more teachers were perceived by their students as cooperative, the higher the students' scores were on cognitive tests.

\section{Instructional Implications}

Making a strong connection to a student results in deep and lasting learning ( Flood, Lapp, Squire, \& Jensen, 2003; Spiro, Coulson, Feltovich, \& Anderson, 1987). According to Flood et al. (2003) there is a consensus among researchers that good readers have a plan for 
comprehending and they use their metacognitive knowledge in an orderly way to implement their plan -- they use a process of thinking that can be taught. The thinking process that is used to comprehend reading is very similar to the process involved in writing, that of synthesizing and analyzing. An effective teacher's ability to teach these thinking strategies successfully could result in a student with knowledge transferability skills that will prepare them for a lifetime of learning. Knowledge transferability, as discussed by Spiro et al. (1987), is a necessary skill if one is to acquire complex knowledge and mastery beyond superficial understanding of preliminary learning. Spiro et al. indicate that knowledge cannot just be handed over to the learner, active involvement in knowledge acquisition is necessary along with "opportunistic guidance by expert mentors" (p. 614). Teachers who have built strong relationships with their students would be able to provide opportunistic guidance to their students because they have intimate knowledge of how their students learn.

Another instructional technique that builds on teacher-student relationships was discussed by Flood et al. (2003). It is the strategy of 'reciprocal teaching' which is a method of teaching comprehension through structured dialogue between teachers and students. As stated 
in Flood, et al., Polinscar and Brown formulated this technique based on Vygotsky's concept of the zone of proximal development. Reciprocal teaching is highly dependent on interaction between teachers and students as readers learn new information (p. 935). Downey (2008), too, recommends the use of reciprocal teaching as an effective instructional strategy; one that requires the building of strong interaction between teacher and students as they "develop an inquiryoriented approach to learning" (p. 60).

Building strong affective relationships with students would give teachers additional instructional capacity that could promote learning from a range of student interests and strengths. According to Hallinan (2008), learning is a cognitive as well as social psychological process. He reports "research has shown that students who like school have higher academic achievement" (p. 271).

\section{Conclusion}

The review of the literature shows the diverse disciplines of researchers who have all investigated the effect that building a strong teacher-student relationship has on the learning environment. While the emphasis on test scores to determine effect teaching and learning has been prevalent in the last decade due to NCLB (2001) and Race to 
the Top (RttT) requirements, there is ample evidence from a number of sources to indicate that building a strong relationship with students also contributes greatly to a successful learning environment.

It is my belief that more research is needed to establish practical application strategies that teachers can use to effectively create a strong and successful relationship with their students. My study addresses how this participant creates a purposefully designed learning environment that has a positive effect on her students' learning. This study participant uses the relationships she deliberately creates with her students to enhance the learning environment. 


\section{CHAPTER 3}

\section{METHOD}

\section{Research Design}

In this research study, I seek to explore the affective domain of teacher effectiveness using a single case study design.

Case study research is a qualitative approach in which the investigator explores a real-life, contemporary bounded system (a case) over time, through detailed, in-depth data collection (Creswell, 2013). Yin (2009) writes that the case study's unique strength is its ability to deal with a full variety of evidence sources such as documents, artifacts, interviews, and observations - beyond what might be available in other types of qualitative methods. He declares that use of the case study strategy has a distinct advantage when a 'how' or 'why' question is being investigated about a contemporary event over which the investigator has little or no control. The case study method allows investigators to retain the holistic and meaningful characteristics of real-life events (Yin, 2009). Yin writes that "case study research involves study in a real life context or setting" (p. 9). 
Stake (1995) purports that qualitative researchers seek to understand a case - to appreciate the uniqueness and complexity of it, its embeddedness and interaction with its contexts (p. 16). Stake contends that the real business of case study is particularization, not generalization -- we take a particular case and come to know it well. He says qualitative study capitalizes on "ordinary ways of making sense" (p. 72). According to Stake, cases seldom exist alone, if there are phenomena in one, there are probably more somewhere else.

Creswell (2009) says "often the distinction between qualitative and quantitative research is framed in terms of using words (qualitative) rather than numbers (quantitative)" (p. 3). That being the case, my use of the qualitative research method to determine a teacher's affective acumen as opposed to evaluating her by her students' test scores would seem like a 'best fit'.

\section{Theoretical Framework}

\section{Social Constructivist}

Most contemporary qualitative researchers promote the belief that knowledge is constructed rather than discovered (Stake, 1995). Social constructivists seek understanding of the world using openended questions so participants can construct the meaning of a 
situation (Stake, 1995, 2010; Creswell, 2009). A major tenet of a constructivist researcher is to look at the processes of interaction among individuals, focusing on the specific contexts in which people live and work. The researcher's intent is to make sense of or interpret the meanings others have about the world (Creswell, p. 8).

The qualitative method in this study is derived from a constructivist viewpoint. Blumer (1978) believes that one has to immerse oneself in a situation in order to know what is going on in it. Creswell (2009) discusses several assumptions regarding constructivism that have a direct impact on how I designed my research inquiry. One premise of the constructivist theoretical framework is that "meanings are constructed by human beings as they engage with the world they are interpreting" (p.8).

Constructivists focus on deeply understanding specific cases of a phenomenon under examination.

My goal in conducting this study is to provide more specificity and greater empirical groundings for how these relationships are created. Identifying specific factors associated with teacher-student interactions will provide valuable information to an educational learning community. After completing an ecological study on 
teacher-student relationships and behavior problems, O'Connor et al. (2011) concluded that, in regard to teacher education, their study demonstrates the importance of "fostering elementary school teachers' awareness of the role of their relationship with students and provides teachers with information as to how to support high quality relationships with their students" (p. 152).

Currently, research on aspects of teaching related to quality in classrooms suggests that teachers' attitudes and beliefs about children are important factors in predicting excellence of education (Pianta et al., 2002). A teacher's personal interactions with his or her students can make a significant difference for students who are at risk for academic failure -- the importance of teachers' relationships with these students cannot be overstated (Downey, 2008).

The use of an illuminative case allowed this researcher to observe how a teacher demonstrates the practice of building student and teacher relationships so other educators can learn from this exemplary and information-rich case. A single case study design will allow for use of replication logic in describing findings. My intent is to elicit my participant's view on what are important and/or 
essential components to developing strong student teacher relationships.

Qualitative interviews are conversations in which a researcher gently guides a conversational partner in an extended discussion, eliciting depth and detail about a research topic by following up on answers (Rubin \& Rubin, 2005). Rubin \& Rubin discuss a variety of qualitative interview structures depending on the focus. Because of the nature of my focus questions, I chose a semi-structured (or focused) format where questions are developed and used "once patterns begin to emerge to obtain more specific knowledge about your research topic" (2005). Through skillful questioning, an interviewer will determine the next question based on carefully listening to the previous answer. A skillful qualitative researcher is one who can quickly adapt to a situation that was totally unexpected (Rubin \& Rubin, 2005; Creswell, 2009; Patton, 2002).

Qualitative research is sometimes defined as interpretive research - investigation that relies heavily on observers defining and redefining the meanings of what they see and hear (Stake, 1995, 2010). He recommends that the researcher provide an opportunity 
for vicarious experience, using a narrative style of reporting, with rich ingredients for this vicarious experience.

Triangulating the data collected will help increase confidence that what is observed and heard has been correctly interpreted. In this study, data triangulation included conducting interviews with the teacher, classroom observations to corroborate interview data, looking at student work samples after teacher intervention, observing and recording teacher-student interactions, and reviewing correspondence.

The purpose of this case study is to explore factors of those teacher-student relationships that contribute to the development of a student's learning environment. This study addressed the following research questions: What specific components of the teacher-student interactions are most essential to a learning environment? How does this teacher describe her process for building relationships with her students?

The results of this case study are practical in nature and include a description of affective characteristics and strategies employed by this teacher that influence the learning environment. 


\section{Setting for the Study}

The research setting for this case study is a large public elementary school in a quiet neighborhood setting in East Bay Rhode Island with approximately 700 students and 75 teachers. The school houses pre-k through grade 5 students and is the only elementary school in town.

The classroom population is diverse, with students of various ethnic and economic backgrounds from this community in East Bay Rhode Island. There are students who have individual education plans for learning difficulties, and personal literacy plans for reading difficulties. Many of the students qualify for free and reduced lunch which puts them in a low socio-economic status.

My purposeful sampling of this classroom generated rich data for interpretation and analysis.

\section{Sampling Design}

In this qualitative study, I used purposeful sampling with an illuminative case, interviewing, and observing this district 'lab teacher' who exhibits highly effective teaching strategies. In this district, Lab Teachers are regular education classroom teachers who have been specially trained in teaching strategies by the math and 
literacy coaches in the district, in specific content areas such as Mathematics and Language Arts. In addition to the content area training they have received, these lab classroom teachers are also continuously mentored by the math and literacy coaches, whereby their instructional practices are observed and critiqued. After the periods of observation, the teachers receive specific feedback designed to move their classroom practice forward.

These teachers have spent years perfecting their craft using current best practices and instructional models. "Finding interviewees with the relevant, first-hand experience is critical in making your results convincing" (Rubin \& Rubin, 2005, p. 68). Rubin \& Rubin propose that, in order to be able to build a theory that has broader implications, a researcher should select interviewees that assure confidence in extending findings beyond the immediate research setting.

\section{General Characteristics of the Participant}

The teacher in this study is an elementary school "Lab Classroom" teacher. This distinction means that she is recognized, in the district she teaches in, as an innovative and master teacher in 
one or more instructional areas. Teachers with this distinction have been specially trained and coached in a content area, such as math, in order to open their classrooms for other teachers in the district to learn from.

I have worked with this teacher in my capacity as a previous administrator in her building and have seen first-hand her teaching practices. Although I am no longer her administrator, this participant exemplifies teaching practices worthy of study. My selection of this teacher fits the criteria of an illuminative case to study and has the capacity to generate information-rich data for the present inquiry.

As participants/members of a Lab Classroom, the teacher and students in this study are accustomed to having people in their classroom observing them, and so are able to remain engaged in their learning and appear remarkably unaffected by the outside observers in the classroom. Because participants are accustomed to blocking outside interference, this setting will enhance my ability to obtain reliable data to analyze.

\section{Statement on Researcher as Instrument}

In qualitative research, the researcher is the instrument, and as such, brings bias into the process. Patton (2002) posits that "the 
human factor is the great strength and the fundamental weakness of qualitative inquiry and analysis - a scientific double edged sword" (p. 433). Patton's advice is to "do the very best with your full intellect to fairly represent the data and communicate what the data reveals given the purpose of the study" (p. 433).

Stake (1995) describes qualitative case study research as highly personal research. He says researchers are encouraged to include their own personal perspectives in the interpretation. Because all research depends on interpretation, one of the main qualifications of a qualitative researcher is experience, according to Stake (1995). He contends we need to use this experience to "know what leads us to significant understanding, recognizing good sources of data, and testing the robustness of our interpretations" (p. 50).

That being the case, this researcher is currently an elementary school principal in northern Rhode Island. My role in this case study will be shaped by my previous experience working in the field of elementary education for the last twenty years, seven of those years as a building administrator in three diverse districts. My teaching experience as a special educator afforded me the opportunity to be embedded in a variety of classrooms, working alongside teachers in 
grades kindergarten through five, providing student support. I

believe these experiences have given me unique insight, understanding, and knowledge of teaching and learning. I also know that these experiences have shaped certain biases (the scientific double-edged sword), although every effort will be made on my part to remain neutral as a qualitative researcher and let the data shape my analysis and interpretation.

Although I conducted this study from the position of administrator, my purpose is to gather information that will enhance the field of education, not as that of an evaluator of teachers. This purpose was made clear to the study participant before the investigation began. The participant was also given a statement of purpose detailing the intent of my role in the study as well as her role. The statement of purpose made clear that it was because of her distinction of Lab Teacher that she has been chosen to participate in this case study as an illuminative; information-rich case.

As a former administrator and teacher in this school, and as both a supervisor and colleague to this teacher in the past, the challenge for me and for the teacher was to remember to define our roles in this study as that of researcher and study participant. I need 
to be mindful that my role is now that of impartial observer and to remind the participant in the study of my purpose for being in the classroom. This will be a paradigm shift that we need to stay mindful of.

A strength I bring to this study is that as an administrator and evaluator of teachers, I have received professional training by the Rhode Island Department of Education in objective observation techniques and objective feedback strategies based on evidence of what was seen and heard during an observation. This training, entitled Workshop for Personnel Evaluating Teachers, occurred over three consecutive summer sessions and included the following instruction and guidance:

- Gathering and Sorting Data using an Observation Template;

- Interpretation of the evidence gathered via Close Rubric Analysis \& Calibration process;

- Developing feedback based on the evidence and data gathered;

- Delivering feedback in an objective manner.

This training and its resulting application through the administrative evaluation process strengthens my researcher investigation practices by grounding my assertions and analysis 
through previous theory and application in the data obtained through interviews and observations.

I also consider my previous role as an educator to be a strength as the researcher conducting this study in that I have years of experiences in classrooms working alongside teachers. Yin (2009) writes that a qualitative researcher should use their own prior, expert knowledge to demonstrate awareness of current thinking and discourse about the case study topic. Stake (1995) also writes of the importance of a researcher's experience as it increases the ability to recognize good sources of data and leads to significant understanding and robust interpretations (p.50).

\section{Data Collection: Sources and Procedure}

Data were collected and analyzed using the suggested practices and sources recommended by Yin $(1994,2009)$ and Stake $(1995,2010)$.

\section{Sources}

A case study database was created and includes the following sources of data:

1) Archival records: I reviewed archived records of e-mail correspondence, memoranda, letters to parents, grading/progress 
reports, personnel files that pertain to the study being investigated. The conditions under which these records were produced as well as the accuracy of the records have been documented by the researcher. 2) Interviews: interview protocols were developed that focused on my case study topic using the responsive interviewing model (Rubin \& Rubin, 2005). The goal of responsive interviewing is a solid, deep understanding of what is being studied. To obtain this depth "the researcher must follow up, asking more questions about what was initially heard" (Rubin \& Rubin, 2005). Semi-structured questions guided the line of inquiry and answers were recorded on the interview protocol form with emergent follow up questions also recorded. Every attempt was made to make sure questions were asked in an objective, unbiased manner.

3) Direct Observation: An observation protocol was developed that focuses on events occurring in real time during field visits. Detailed notes, photographs, and observations were recorded on the observation protocol with the date, time and setting recorded for each observation.

4) Member Checking: A copy of the information obtained from the interviews and observations was provided to the interviewee for 
accuracy of interpretation and correction if necessary. The participant reviewed the data, as well as the interpretation of the researcher.

5) Data triangulation from the above sources provides corroborating evidence of the topic being studied and creates a chain of evidence to support the case study conclusions. According to Stake (2010) evidence is an attribute of information and contributes to understanding and conviction. As such, it should be valid and relevant and allow people to attain a deeper conviction of how something works.

\section{Procedure}

The following formal case study protocol was developed to enhance the reliability of this case study research.

The participant completed an initial audio-taped interview, and then a follow-up interview was conducted for clarification purposes. The interviews were semi-structured, using prepared interview questions with clarifying or probing question interspersed by the interviewer.

A general interview guide was used with semi-structured interview questions in an emergent design format developed to gain 
information from the interviewee. Follow-up questions designed to clarify and refine analysis were developed based on the unique responses of the participant. The questions for the interview guide were designed to be interpretive and were drawn from a review of the literature.

Following the interview, classroom observations were conducted using the Marzano Observational Protocol (1999) (see Appendix A) and the Teacher Expectations for Student Achievement (TESA) Protocol (see Appendix G) to gather further evidence to corroborate information obtained during the interview. These observations occurred during a variety of content areas and at various times of day.

Follow-up interviews were conducted to address researcher questions that came up during the observations and needed further clarification. These interviews lasted approximately twenty to thirty minutes each.

\section{Data Analysis}

Patton (2002) advises "because each qualitative study is unique, the analytical approach will be unique. Because qualitative inquiry 
depends, at every stage, on the skills, training, insights, and capabilities of the inquirer, qualitative analysis ultimately depends on the analytical intellect and style of the analyst" (p. 433).

Data were analyzed following the steps outlined by Rubin \& Rubin (2005) for Responsive Interviewing analysis techniques: 1) Recognition: finding the concepts, themes, events, and topical markers in interviews;

2) Clarify and Synthesize: through systematic examination of the different interviews to begin understanding of the overall narrative;

3) Elaboration: generating new concepts and ideas after clarification and synthesis;

4) Coding: systematically labeling concepts, themes, events, and topical markers, giving them a brief label to designate each and then marking in the interview text where they are found;

5) Sort: sorting the data units and ranking them and building relationships toward a theory (p. 207).

\section{Interview Guide}

A general interview guide was used with semi-structured interview questions in an emergent design format developed to gain information from the interviewee. The questions for the interview 
guide were designed to be interpretive and were drawn from a review of the literature.

A Responsive Interviewing protocol was developed with followup questions and probes. This allowed the researcher to ask additional questions to explore the particular themes, concepts, and ideas introduced in the initial interview. Probes were also part of the responsive interviewing protocol I used as a technique to keep the conversation going in order to complete an idea, fill in a missing piece, or request clarification (Rubin \& Rubin, 2005).

\section{Terms of Validity and Reliability}

Credibility and authenticity are major components of validity in qualitative research. Qualitative validity means that the researcher checks for the accuracy of the findings by employing certain procedures, while qualitative reliability indicates that the researcher's approach is consistent.

In regard to validity with qualitative research, Stake (1995) created a list of 'Things to Assist in the Validation of Naturalistic Generalizations' (p. 87).

1. Include accounts of matters the readers are already familiar 
with so they can gauge the accuracy, completeness, and bias of reports of other matters;

2. provide adequate raw data prior to interpretation so that the readers can consider their own alternative interpretations.

3. describe the methods of case research used in ordinary language including how the triangulation was carried out. 4. make available information about the researcher and other sources of input (p. 87).

Stake believes it is the responsibility of the researcher to assist readers to arrive at high quality understandings of the findings. The researcher's analysis and interpretations have to parallel that of the readers'.

Triangulating different data sources of information by examining evidence from the sources and using it to build a coherent justification for themes adds validity to the study (Patton, 2002;

Creswell, 2009; Yin, 2009; Stake, 2010) and also serves as support for Stake's 'high quality of understandings' (p. 88) that he asserts a researcher must obtain.

I have used multiple sources of evidence to collect my data, keeping careful notes and using a credible subject who is considered 
a model teacher in the district. My interpretations are well grounded in the data I collected employing triangulation in my design consideration. I was persistent in my observations in order to generate rich data for analysis and interpretation.

\section{Ethical Issues}

Deyhle et al. (1992) argue that "research in education, whether quantitative or qualitative, is basically applied research. The results of such research almost always have immediate or potential practical applications or implications" (p.610).

Ethical issues are serious concerns for all qualitative researchers mostly because of the relationships that are developed. "Unique ethical considerations are inherent in designing a qualitative study because the success of such research is based on the development of special kinds of relationships between researchers and informants" (p. 618). My relationship to this study participant began as a fellow teacher and it was the development of a close personal relationship that allowed me to obtain important information. Being mindful of Deyle, et al.'s (1992) caution regarding how information is gained and divulged, I was explicit in 
describing the purpose of my investigation with this study participant.

While many qualitative researchers (Stake, 1995; Yin, 2009; Deyle, et al., 1992) understand that there are no set 'ethical rules' in place for qualitative researchers to follow, best practice dictates that mindful and reflective strategies should be at the forefront of the study design. To that end, my interaction with this study participant included opportunities for questions, clarification of process, and assurance of confidentiality.

\section{Resources Required}

(1) IPAD for note taking and recording interview sessions; (2) a private space to conduct interviews; (3) computer software to assist with data management and analysis to be purchased by researcher; (4) copies of all letters and forms necessary for the participant in the study; (5) \$10 gift card to be purchased by the researcher for study participant; (6) interview and observation protocol sheets; (7) access to student records and progress monitoring data; (8) approval by the Institutional Review Board; (9) the cooperation of the district the interviewee teaches in. 


\section{CHAPTER 4}

FINDINGS

In this chapter I analyze interview statements and observation data using protocols that reflect components of effective teacher - student relationships as described in the literature review. The data have been sorted, coded, categorized, and reviewed for relevance. The analysis process I used is a hybrid of case study analysis methods guided by Stake (1995, 2010), Yin $(2003,2009)$ and Rubin \& Rubin (2005).

This single case study produced a synthesis of information that guides the classroom teacher in this study in the development and maintenance of her relationships with her students. The resulting analysis and interpretation provides a description of major themes that developed regarding strong teacher student relationships, as well as, specific components to the interactions considered essential for her students' learning environment.

Stake (1995) says there are two strategic ways that researchers gain meaning about cases. One is through direct 
interpretation and the other, through aggregation of instances until something can be said about them as a class (p. 74). He purports that both of these strategies are necessary with case study analysis with the most important meanings coming from reappearance over and over.

\section{Interview and Observation}

I interviewed the participant in this study on three separate occasions. The purpose of the first interview was to have her describe her process for building a relationship with her students and share any anecdotal evidence she had to support what she was saying.

This initial interview was followed up with a classroom observation where I took field notes pertaining to verbal and physical interactions the teacher had with her students, as well as the physical layout of the classroom. I used this information as part of my triangulating process.

The second interview was to listen for more depth and detail, and to clarify observation data. By listening for key ideas, words, or evolving themes that I felt were important to my research questions, I used this interview to probe for meaning in 
order to gain clarity and precision in my interpretation of the data being gathered. At this point I was listening for specific components of the teacher's interaction with her students that she considered essential to the learning environment she created. Another shorter observation followed. This information would allow me to begin to answer my second research question, which was 'to describe the process this teacher uses for building relationships with her students'.

The third meeting with my participant was to gain more specific triangulating data; and to ask for student work samples with teacher feedback notes, copies of emails to parents, grading data, and ask final questions before beginning my analysis and interpretation.

Analysis of Findings

Yin (2003) says "data analysis consists of examining, categorizing, tabulating, or otherwise recombining the evidence to address the initial propositions of a study" (p. 109). He suggests that every investigation should have a general analytic strategy to guide decision-making. For guidance in analyzing 
my data, I turned to Rubin and Rubin (2005) and their analytic strategies.

Rubin and Rubin write that data analysis is the process of moving from raw interviews and observations to evidence-based interpretations; the objective being "to discover variation, portray shades of meaning, and examine complexity" (p. 202). To begin this data analysis interview text is broken down into data units and then, the units that refer to the same topic are combined. Rubin \& Rubin define data units as blocks of information that are examined together. Once these data units are established, the coding process continues by labeling each data unit and sorting these codes into single categories. According to Rubin and Rubin "using published literature to suggest concepts and themes by which to code is perfectly legitimate as it will help you relate your findings to what others have already written" (p.209). That being the case, for categorical aggregation I used portions of the Teacher Expectations for Student Achievement (TESA) rubric and Marzano's Observation Protocol (Appendix G and A) categories that were specific to teacher relationships with students. TESA is an interaction model and rubric based on the 
research of Thomas Good and Jere Brophy $(1974,1976)$ that pertains to teacher and student relationships. Marzano's (2009) protocol is well-grounded in his research on teacher effectiveness and teacher relationships with students. During the sorting and labeling process, using these categories gave me the ability to have clarity and consistency that was well grounded in research.

I began with a line-by-line analysis of what the teacher was saying as she answered my interview questions. I asked myself "What is this particular comment an example of"? Using Marzano's Protocol response statement: "I can see the computers, the book cases, the work table, etc." was initially coded as Occupying Entire Room. "I can look up and comment and provide feedback" was initially coded as Monitoring the Room.

My analysis also included reduction by checking each statement for relevance to the research questions. Table 1 provides an example of relevant interview statements and observation data and how they were initially coded using Marzano's Short Observation Protocol (2009). This protocol (Appendix A) is organized to represent three different categories 
which include nine elements of specific observable behaviors

and interactions. Specific questions in each category and possible examples of evidence guide the use of this protocol.

Marzano recommends only using this protocol if you have a clear understanding of The Art and Science of Teaching (Marzano, 2007) - which I do from my doctoral coursework and attending Marzano workshops.

Table 1

Sample of Transcript statements coded using Marzano Protocol

Interview transcript coding in parenthesis

Observational coding in bold text in parenthesis

I: "What affective qualities do you think a teacher needs to have to be a good teacher?"

R: Patience, lots of structure, and providing information so the students know what they need to learn.

They need to know what is expected of them.

And then you need to follow through and constantly monitor to make sure they are doing what you've asked them to do.

I can't stress the importance of structure and patience -- structure in every aspect of structure.

Understanding what it is in every moment of the day of what you need to be doing. 
I think about the needs of students and also a lot about personalities.

CODE: (monitoring/clear expectations/Establishing Routine/Understanding

\section{Students) (Section I; \#1 \& 2 of Marzano Protocol)}

R: The tone of your voice is very important.

You need to choose words that are kind and caring such as "I love you but this is wrong."

You also need to tell the student why he/she is being disciplined so they can make better choices.

I teach through the use of humor.

You kind of figure out the child and learn what they need.

There are a lot of things I have invested in to help children be successful.

CODE: (affect-caring/use of humor/tone) (Section III; \#14 Marzano

\section{Protocol)}

I: You talked about 'community' in your classroom; how do you build a sense of community in your classroom? Why is that important?

R: You begin building trust and expectations in the beginning of the year.

Building accountability helps to establish trust and responsibility.

We have meetings to discuss whatever is affecting the class at the time and we discuss it together.

We don't meet every day but for example if something happened at recess we will get together and discuss it as a class.

Rules are established using whole class discussion.

We create expectations together and consequences together -- I think that is a key part of it. 
Also, all my materials are organized and labeled so kids take what they need. It's important they know where the materials are they need and can easily access them. Everything is 'community' - take what you need.

Students have jobs and apply for the classroom jobs - gives them a sense of ownership of the classroom.

It's building a community that everyone is a part of.

I call parents and build a relationship with parents.

Phones are in the classroom so I can call parents from the classroom building a partnership with the parents.

I also do a lot of emailing (to parents).

CODE:(physical layout for learning/organizing materials/acknowledging

adherence to rules and procedures/clear expectations/parent

interaction/community) Section I, \#5; Section III, \#12 Marzano Protocol)

I: "Ok so if you have something you want to discuss you call a class meeting"?

R: Yes so we can all discuss it together and look at what rule was broken, whose feelings were hurt, etc.

So we're all on the same page and working together.

CODE:(Monitor behavior/interaction/adherence to rules) Section I, \# 4 Marzano Protocol)

I: Describe the physical arrangement of your classroom. Is that purposeful?

R: Yes, definitely, it's not random.

First let's talk about how I group my class and the physical location.

Physical arrangement is purposeful.

They are sitting in teams and I think that is important. 
They start at the rug, then to the computers, then the work table, then their seats, or with me at the table.

Students work in 'teams' and desks are grouped that way so they work collaboratively.

Physical arrangement of the room is such that nothing is blocking my view from anywhere in this room.

I can see the computers, the book cases, etc. so I can look up and comment and provide feedback.

CODE: (physicalstructure/purposefulenvironment/feedback/movement/team

work) (Section I \#5; Section II \#2 \#10 \#16; Section III \#4 Marzano

\section{Protocol)}

I: Why is this important?

It's a structure thing - because it helps them and I don't have to do a lot of directing.

They know where they are going after each station and it follows a logical sequence. Everything is labeled and easily identified for the students.

I don't have to keep telling them where to go; they just follow the classroom instruction activities.

All materials are organized and labeled so kids take what they need.

It's important they know where the materials are that they need and can easily access them.

CODE:(Routines/physical structure/traffic patterns/organizing materials/)

(Section I \#5 \#4; Section II \#16 \#18 Marzano Protocol) 
As I indicated in Chapter Three, my initial interview questions were drawn from a review of the literature. I asked questions about purposeful design of the classroom and followed up with specific observation because Marzano (2003) considers classroom organization an essential element to student and teacher relationship building. I was interested in finding out how this teacher organized and set up her classroom each year and her rationale for doing so.

Coding interview comments like "All materials are organized and labeled so kids take what they need. It's important they know where the materials are that they need and can easily access them" and "I arrange my room so nothing is blocking my view" led me to make it a point to observe the physical classroom environment and placement of furniture, equipment, and materials with an eye toward how that contributed to the teaching and learning environment. When asked to describe the physical arrangement of the classroom, I asked if it was important to how she taught and to her relationship with her students. Her response was "it is definitely important, it is not random". 
My observation supported interview comments that the students' ability to anticipate the next step in their learning was an effective teaching strategy as it allowed for lengthier instructional time with little to no interruptions and fostered the students' sense of ownership of the classroom environment they were learning in. The observational code that corresponded with the interview line codes was "classroom traffic patterns". This analysis led to a category of Classroom Layout with Purposeful Design.

I used the memo writing process to help me thoroughly analyze the codes I had developed through the line analysis of the interviews.

One memo notation I made regarding the physical environment of the classroom that the teacher created was how important that appeared to be in supporting student learning as it extended the instructional time without interruptions. Students didn't need to keep asking the teacher what to do next or where their materials were.

Memo notation: In creating the student's classroom learning environment, an area of importance is the physical placement and design of the classroom furniture and materials. A purposeful design can support instruction 
and student learning both academically and behaviorally.

I then returned to my interview transcript and observation data and analyzed each line looking for relevant data using the Teacher Expectations for Student Achievement (TESA) Interaction Model (Appendix G). In this model, there are fifteen teacher interactions arranged in three categories with five actions in each category. This model also has specific criteria and examples of possible evidence for inclusion in each category. The three categories are Response Opportunities, Feedback, and Personal Regard. Table 2 provides an operational definition of the corresponding teacher interaction for each category.

Table 2

TESA Interaction Model

\begin{tabular}{|c|l|l|}
\hline $\begin{array}{l}\text { Response } \\
\text { Opportunities }\end{array}$ & Feedback & $\begin{array}{l}\text { Personal } \\
\text { Regard }\end{array}$ \\
\hline $\begin{array}{c}\text { Equitable Distribution: } \\
\text { Teacher provides } \\
\text { an opportunity } \\
\text { for all students to } \\
\text { respond }\end{array}$ & $\begin{array}{l}\text { Affirm/Correct: } \\
\text { Teacher gives } \\
\text { feedback to } \\
\text { students about } \\
\text { their classroom } \\
\text { performance }\end{array}$ & $\begin{array}{l}\text { Proximity: } \\
\text { Significance of } \\
\text { being } \\
\text { physically } \\
\text { close to } \\
\text { students as they } \\
\text { work }\end{array}$ \\
\hline $\begin{array}{l}\text { Individual Help: } \\
\text { Teacher provides } \\
\text { help to individual }\end{array}$ & $\begin{array}{l}\text { Praise: } \\
\text { Teacher praises } \\
\text { the students' }\end{array}$ & $\begin{array}{l}\text { Courtesy: } \\
\text { Teacher uses } \\
\text { expressions of }\end{array}$ \\
\hline
\end{tabular}




\begin{tabular}{|c|c|c|}
\hline students & learning & $\begin{array}{l}\text { courtesy with } \\
\text { students }\end{array}$ \\
\hline $\begin{array}{l}\text { Latency: } \\
\text { Teacher allows } \\
\text { student enough } \\
\text { time to think over } \\
\text { question before } \\
\text { assisting or } \\
\text { ending } \\
\text { opportunity to } \\
\text { respond }\end{array}$ & $\begin{array}{l}\text { Reasons for } \\
\text { Praise: } \\
\text { Teacher gives } \\
\text { useful feedback } \\
\text { for the students' } \\
\text { learning } \\
\text { performance. }\end{array}$ & $\begin{array}{l}\underline{\text { Personal }} \\
\underline{\text { Interest \& }} \\
\text { Compliments: } \\
\text { Teacher asks } \\
\text { question, gives } \\
\text { compliments, } \\
\text { makes } \\
\text { statements } \\
\text { related to a } \\
\text { student's } \\
\text { personal } \\
\text { interest }\end{array}$ \\
\hline $\begin{array}{l}\text { Delving: } \\
\text { Teacher provides } \\
\text { additional } \\
\text { information to } \\
\text { help student } \\
\text { respond }\end{array}$ & $\begin{array}{l}\text { Listening: } \\
\text { Teacher applies } \\
\text { active listening } \\
\text { techniques with } \\
\text { students }\end{array}$ & $\begin{array}{l}\text { Touching: } \\
\text { Teacher } \\
\text { touches student } \\
\text { in a respectful, } \\
\text { appropriate and } \\
\text { friendly } \\
\text { manner }\end{array}$ \\
\hline $\begin{array}{l}\text { Higher Level } \\
\text { Questioning } \\
\text { Teacher asks } \\
\text { challenging } \\
\text { questions that } \\
\text { require more than } \\
\text { simple recall }\end{array}$ & $\begin{array}{l}\text { Accepting } \\
\text { Feelings: } \\
\text { Teacher accepts } \\
\text { students' } \\
\text { feelings in non- } \\
\text { evaluative } \\
\text { manner. }\end{array}$ & $\begin{array}{l}\text { Desisting: } \\
\text { Teacher stops } \\
\text { misbehavior in } \\
\text { a calm and } \\
\text { courteous } \\
\text { manner }\end{array}$ \\
\hline
\end{tabular}

Table 3 provides a sample of interview statements and classroom observation notes that corresponded to each TESA category and action. 


\section{Table 3}

Interview and observation codes using TESA interaction model.

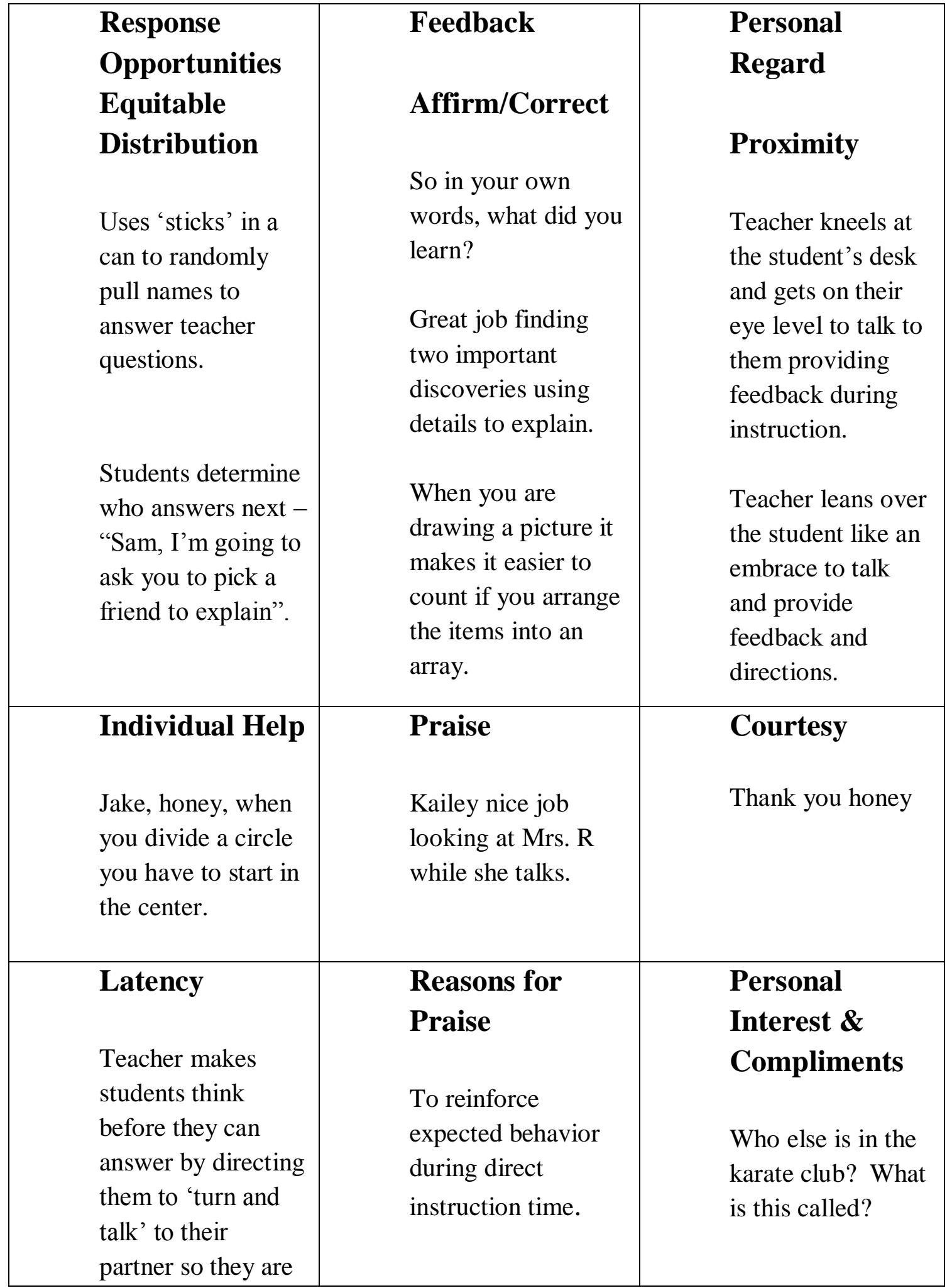




\begin{tabular}{|c|c|c|}
\hline $\begin{array}{l}\text { ready to explain } \\
\text { their answer. }\end{array}$ & & $\begin{array}{l}\text { Show us what to } \\
\text { do --(occurred } \\
\text { during an exercise } \\
\text { break) }\end{array}$ \\
\hline $\begin{array}{l}\text { Delving } \\
\text { Explain that to me } \\
\text { I'm confused - did } \\
\text { she actually ...? } \\
\text { My question now is } \\
\text { - put on your } \\
\text { thinking cap. }\end{array}$ & $\begin{array}{l}\text { Listening } \\
\text { I listened to him talk } \\
\text { about home and } \\
\text { things he liked to do } \\
\text { and he said he liked } \\
\text { the IPAD. } \\
\text { (Intentionally } \\
\text { looking for a } \\
\text { motivator) } \\
\text { I just paid attention } \\
\text { to them (to } \\
\text { determine what they } \\
\text { needed to learn). }\end{array}$ & $\begin{array}{l}\text { Touching } \\
\text { Teacher fixes } \\
\text { Grace's hair while } \\
\text { she's asking a } \\
\text { question. }\end{array}$ \\
\hline $\begin{array}{l}\text { Higher-Level } \\
\text { Questioning } \\
\text { Inferring - Do you } \\
\text { think you can } \\
\text { figure out how old } \\
\text { she is now? }\end{array}$ & $\begin{array}{l}\text { Accepting } \\
\text { Feelings }\end{array}$ & $\begin{array}{l}\text { Desisting } \\
\text { Teacher quietly } \\
\text { puts her finger to } \\
\text { her lips and makes } \\
\text { eye contact with } \\
\text { the student for } \\
\text { quiet signal to stop } \\
\text { behavior. } \\
\text { Was Ellen } \\
\text { listening? How do } \\
\text { I know? (Students } \\
\text { respond with a } \\
\text { description of } \\
\text { expected listening } \\
\text { behaviors ie. } \\
\text { Looking at } \\
\text { speaker, etc.) }\end{array}$ \\
\hline
\end{tabular}


Once the line-by-line interview and observation coding was completed, using both the Marzano and TESA protocols for guidance, I began looking for patterns in the coded data in order to sort them into categories. I started the process of categorizing my codes, being mindful of Glaser's (1967) concerns of forcing data into preconceived categories. He stresses that the data need to have enough relevance to be admitted into a category.

Stake (1995) advises that "with instrumental case studies, the need for categorical data and measurements is greater as important meanings come from reoccurrence over and over" (p. 78).

Once all the transcript and observation notes were coded and categorized, the process of convergence began where I looked for relationships within my coding across both protocols. I began to look for overlapping components of categories from both protocols in order to determine recurring themes describing what my participant considered most essential to building teacher and student relationships as well as key components considered essential to an effective learning environment. Once these core 
elements emerged from the data, I synthesized the categories integrating the overlapping elements of each into contextual themes with supporting concepts. Classroom observations helped further refine and support my coding to see where they converged with a recurring regularity, connecting and overlapping into one category.

According to Patton (2002), qualitative analysis is not about providing numeric summaries, it is transforming data into findings. "Although no one formula exists for that transformation, guidance is offered in making sense of massive amounts of raw data that will allow the researcher to identify significant patterns and construct a framework for communicating the essence of what the data reveal" (p. 432).

Searching for patterns and convergence between the interview and observation data allowed me to construct a framework of categories for interpretation purposes.

Figure 1 illustrates the data analysis steps taken to create the resulting contextual categories. These steps are a composite of the analytic strategies of Stake (1995, 2010), Yin (2003), and Rubin \& Rubin (2005). All had comparable methods of analysis for case 
study research following the basic tenets of grounded theory; however, there were specific components to each researcher's methodology that I considered a good fit to answer my research questions.

\section{Research Questions}

The research questions guiding this study are:

1. What specific components to teacher and student interactions are essential to a learning environment?

2. How do teachers describe their process for building relationships with their students?

When writing the case study report, Stake (1995) suggests organizing the report in a way that contributes to the reader's understanding of the case. He recommends including vignettes into case study reports so the readers "immediately start developing a vicarious experience" of the case being studied (p.123).

The following composite of related concepts is created from the recurrence and overlapping of interview transcripts and observation data. Through the process of convergence, I merged relevant data from corresponding categories in the Marzano and TESA protocols into one contextual category. Following the suggestion of Stake 
(1995) I used pre-established codes initially, then combed through the data again separately looking for new categories to create. He says "important meanings come from reoccurrence over and over and by isolating these repetitions, critical evidence of our assertions emerge" (p. 78).

After careful analysis of my data, four primary categories emerge in answer to research question \#1: What specific components to teacher and student interactions are essential to a learning environment? These four primary concepts include critical components within that provide support for these concepts. I used recurring evidence from teacher interview statements and classroom observation notes, as well as corresponding criteria in each protocol to support the creation of each contextual category. 
1.Reduction - Analyze all interview statements for relevancy

2. Refine, Clarify, \& Integrate statements

3. Coding, Sorting, and Labeling of data

4. Convergence of Coded Data relationships within codes

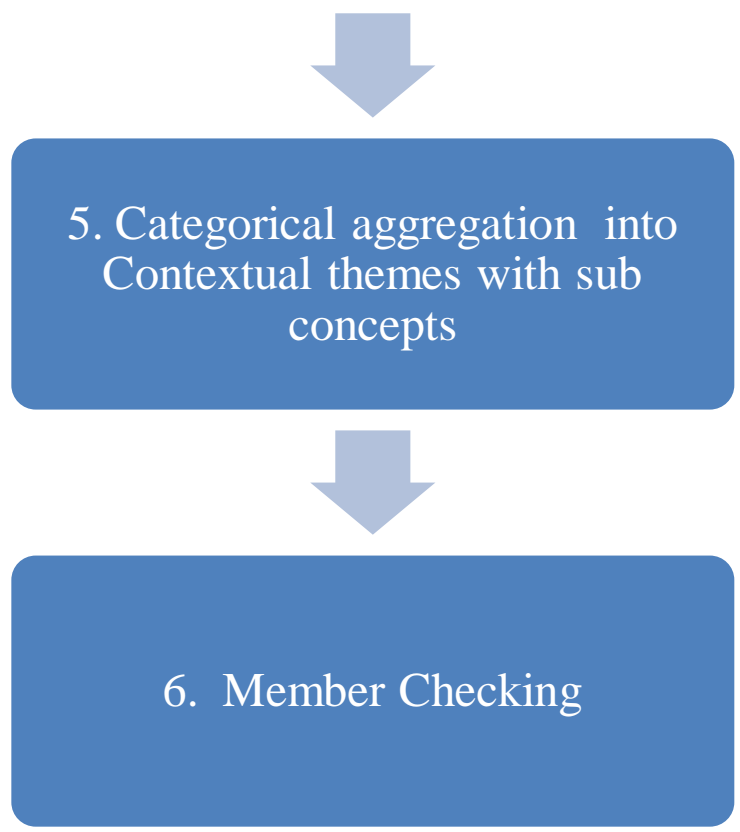

Figure 1. Data analysis steps for contextual categories. 


\section{Presentation of Results}

The four specific categories are Classroom Climate, Classroom Layout, Teacher Interaction, and Instructional Delivery. They reflect a composite of several aspects of Marzano's protocol and the TESA Interaction Model that were considered essential to the study participant. The essential components were included in each category due to a preponderance of evidence after the convergence process was completed.

\section{Contextual Category 1: Classroom Climate}

\section{Classroom Climate -- Essential Components}

\section{Build trust with students}

Set clear and consistent expectations

Create consistent routines and procedures

Create consequences for behavior together

Build a sense of community within the classroom

Create student 'jobs' for sense of ownership of classroom 
Classroom climate refers to the culture of respect and caring the classroom inhabitants have that is purposely created by the teacher. This category begins the relationship-building process and was created from the convergence of components of Marzano's Sections I and III, and TESA Interaction Model section Personal Regard.

The research participant explained that for her, building a relationship with her students begins with the classroom environment. She purposely creates a climate of community within her classroom that her students feel an integral part of. As she explains:

You have to build trust between yourself and your students. Building accountability helps to establish trust and responsibility. Little things like being held accountable for your behavior and for completing your job. Students have classroom jobs they have to apply for. It gives them a sense of ownership of the class. She tells them "it's your classroom you don't have to ask me". I am building a community that everyone is a part of. They also earn privileges and rewards all the time. It's all positive and helps to foster independence. 
The classroom climate also includes clear expectations that are established together through consistent routines and procedures. She explains:

We create expectations for behavior and consequences together as a class in the first week of school. I think that is a key part of creating my classroom climate. I don't go in and tell them these are the rules, we establish them together. Providing information so the students know what they need to learn is also very important. They need to know what is expected of them.

When the teacher has to address an unexpected behavior, she refers the student back to the established expectations by saying, for example:

You are telling me this is what you are doing. However, if we are working in a group how should it look? What should I see? What should it sound like?

The participant stated that she adjusts student behavior calmly and courteously, reinforcing the culture of respect and rapport that has been created and maintained. She wants her personal regard for her students to be clearly evident to them through consistent adherence to the established routines and procedures. 


\section{Contextual Category 2: Classroom Layout with Purposeful Design}

Classroom layout refers to the physical environment of the classroom and reflects the purposeful placement of furniture, equipment, and materials to support student learning. This category reflects the relationship the teacher purposefully creates with her students as they interact within their learning environment. This category is created from the convergence of components of Marzano's Section I and the researcher's interview and observation data.

\section{Classroom Layout with Purposeful Design Essential Components}

\begin{tabular}{l}
\hline Work Stations \\
Organization of Materials \\
Traffic Patterns \\
Physical Space \\
\hline
\end{tabular}

The participant discussed the physical placement of desks, computers, bookcases, rug, and materials the students would need to complete their work. In her words, "it is not random"; it is the 
building block to how she and her students interact with each other and with their learning environment.

She describes the purposeful layout of the physical space in her classroom and her rationale for it this way:

My rug takes up a large area of my room because they need somewhere to sit together during whole group instruction --pair sharing, listening, and constantly turning and talking to other students. Bookshelves run parallel to the computer station so students on the rug playing a math game are not distracted by the computer people. A long table is set up with materials students need like highlighters and sticky notes so students have a quiet place to work and spread out.

Work stations are areas created for specific purposes such as writing, math, science experiments, or time with the teacher for small group lessons. Work stations can also be specifically designed for a particular student who has unique needs. As this teacher participant describes it,

Some children can't sit still and I noticed 'she' didn't like being around people while working so I made adjustments for her to accommodate 
her learning style and created a space she could

go where she was more comfortable in the

classroom - behind my desk.

Traffic patterns are also purposely created in the classroom to create a consistent flow from one part of the lesson, or work station, to another. The participant explains that this consistency lends itself to a sense of ownership of the classroom and personal responsibility for their work. It also allows her to interact with her students. As the teacher describes,

Physical arrangement is purposeful. I wanted class stations. They are in teams and I think that is important. They start at the rug, then to the computers, then the work table, then their seats, or with me at the table. Physical arrangement of the room is such that nothing is blocking my view from anywhere in this room. I can see the computers, the book cases, etc. so I can look up and comment and provide feedback.

According to the study participant, this ability to provide periodic feedback as students are working allows her to interact with 
her students in a purposeful way and provides opportunities for teacher and student interactions that are essential to student learning.

As for classroom supplies and materials, the study participant indicates that:
All materials are organized and labeled. Kids take what they need. It is important they know where the materials are that they need and can easily access them. Everything is 'community' - just take what you need.

During a follow up interview, the study participant explained that she directs students to where all the necessary supplies and materials are during the first week of school. Labels are reviewed with the students so she is confident all understand the task. The teacher indicates that she will make a game of it so that finding where the appropriate materials and supplies are becomes part of their routine. This process lends itself to being part of a community of learners that the study participant builds as part of her relationship with her students. 


\section{Contextual Category 3: Teacher Interaction Behaviors}

Teacher interaction behaviors refer to specific actions that allow for positive communication between the teacher and her students.

There were eight identified practices that this teacher exhibited during observation and explained during interviews; all considered essential to teacher and student relationships in a learning environment. This category is created from a convergence of Marzano's Section III and TESA Interaction Model Feedback, and Personal Regard.

Teacher Interactions

\begin{tabular}{l}
\hline Tone of Voice \\
Proximity to Students \\
Feedback to Students \\
Personal Discourse \\
Active Listening \\
Use of Humor \\
Use of Praise \\
\hline
\end{tabular}


The research participant described in interviews, and

demonstrated during observations in the classroom, how she used humor, praise, and a mild even tone of voice consistently when interacting with her students.

\author{
"Kailey nice job looking at Mrs. R \\ while she talks". \\ "You need to be stern but caring". \\ "The tone of your voice is very important". \\ "You need to choose words that are kind \\ and caring". \\ "Use of humor helps with relationships \\ with students. I use humor a lot when \\ interacting with my students". \\ "I teach through the use of humor".
}

Active Listening techniques were explicitly taught and modeled by the teacher. This example was observed during whole group instruction and recorded in my observation notes:

Teacher asks "Was Ellen listening? How do I know?" (Students respond with a 
description of expected listening behaviors

i.e. looking at speaker, etc. and then follow

them.)

Proximity to students refers to being within arm's length

of the student. Many instances of proximity were witnessed during observations. When the class was on the rug for whole group instruction, very often the teacher would sit cross legged on the rug with the students as part of their circle and instruct from that position. Of note were the following examples:

- Teacher kneels at the student's desk and gets on their eye level to talk to them providing feedback during instruction.

- Teacher leans over the student like an embrace to talk to them and provide feedback and instruction.

Personal discourse was also considered an essential component to how this teacher built and maintained her relationship with her students often sharing her own personal stories and pictures of her family and pets with her students. The study participant believed this made her students feel like they were an important part of her life outside of school as well as in the school setting. She did 
not want her students to feel a "disconnect" between them and her family.

Feedback is continual throughout the day for this teacher. Everything about her instructional time and classroom layout is organized so she can have frequent contact with her students as they are learning. In her words,

\author{
"You need to figure out the child and \\ learn what they need. I look at \\ student work and decide what to \\ teach and how to teach it. I give \\ students constant feedback".
}

\title{
Contextual Category 4: Delivering Instruction
}

Delivering Instruction category contains specific methods of interaction between teacher and student during instructional time that build on the teacher - student relationship as it applies to learning. This category is created from convergence of Marzano's Section I and III and TESA Interaction Model Feedback and Response Opportunities. The interaction between the teacher and student that affects the learning 
process is a powerful use of relationship building in the classroom.

These essential components of the interaction between teacher and student have a direct impact on the instruction and learning that occurs at every moment of engagement.

Delivering Instruction- Essential Components

\title{
Scanning and Monitoring
}

Wait Time

Student Interests

Active Listening

Physical Movement

Motivating Student

Equitability

Animated Delivery of Instruction

\author{
Re-Teaching
}


As stated previously, scanning and monitoring the students in this classroom is continual and serves to let the students know that the teacher is actively engaged in their learning at all times and that she is available to them for assistance and guidance. She says,

\author{
"I am always looking at what the groups \\ are doing and I'm commenting so they \\ know I am aware of what is going on. \\ You have to know your kids to know \\ what they can and can't do. When they \\ are ready for you, you need to be able to act".
}

Creating learning opportunities that captivate student interests is also a purposeful act for this teacher and reflects the relationships she has built with her students. She is engaged in 'active listening' throughout the day to capture student interests.

I think about the needs of students and also a lot about their personalities. You kind of figure out the child and learn what they need. There are a lot of things I have invested in to help children be successful. I listened to them talk about home and things they 
liked to do and use that information

to motivate them and create lessons.

Equitability refers to a student's equal chance to be part of a lesson, activity, or response to a question. This participant uses 'sticks' in a can to randomly pull names to answer teacher questions and participate in an activity. Other students can also determine who answers next, for example, "Sam, I'm going to ask you to pick a friend to explain". According to the study participant: "kids like when their peers notice them and their work; it provides positive reinforcement for them" and promotes relationship building.

The study participant uses movement and animated voice to deliver instruction and maintain student engagement in the instruction. Some examples of this that were observed by this researcher were:

- frequent movement breaks that incorporate yoga stretching practices "let's stand and stretch real quick because we have to move on to math".

- sitting on an exercise ball during lessons instead of a chair

- teacher moving from group to group in animated conversation

- having a student demonstrate a two minute exercise from their karate class

- sprinkling fairy dust (glitter) on students "hocus, pocus, focus" to maintain focus 
Re-teaching is also an essential component to the learning environment and is built on the relationship between the teacher and student. When asked what she does when students 'don't get it' she replied: "Sometimes I just stop them and try it a different way, if they are not getting it still I keep trying different ways until they do. I finally figure out what works for them". "Sometimes I go home and go on line and research thinking 'OK they didn't get this so what is another way I can do it' then I re-visit it the next day". Instruction is persistent until the desired level of learning has occurred.

Research Question 2: How do teachers describe their process for building relationships with their students?

In answer to research question 2, the study participant had this to say as she described her process for building relationships with her students.

1). She begins by building trust with her students and their parents from the first day of school. This is accomplished through frequent contact and active listening to get to know her students and their families. She shares her own personal stories and pictures with her students to draw them into her life and make them feel a strong connection to her. She 
introduces herself to parents and guardians and solicits their help to volunteer in the classroom, thereby drawing them into the teacher and student's classroom environment. This relationship building allows them to feel an integral part of the classroom. Examining emails to parents as triangulating evidence corroborated how the parents feel supported by the teacher. Both the student and their parents view the relationship as a partnership. Students realize they have a role and responsibility in that partnership and it is to become learners and complete their school work. The teacher states that "building accountability helps to establish trust and responsibility". A phone in the classroom allows for immediate contact with a parent if there is a problem. The study participant indicates that this immediate parent contact reinforces the relationship between the student and teacher because they realize how invested she is in the child's learning and how invested their parents are in their learning. The study participant offers this anecdotal support:

"This year I have a student struggling in math so his mother and I do a lot of communicating and she is helping out at home as well. I give her the information. Part of the mother's problem was that her child was coming home with homework and she didn't know what he was talking about and didn't know how to help him. I went online to 
Google image and inserted that in her email and sent it to her so she could see what we were talking about in class and now she can help her child".

In addition, the teacher sends home support materials to parents to assist with homework and to reinforce the daily learning. She points out that this adds to the relationship building process because students feel supported and parents feel that the teacher knows their child well. All are invested in this community of learners the teacher has created.

2). The study participant describes her next steps in the process as establishing rules and consequences together that address expected behavior in the classroom. This behavior includes interaction between teacher and student, as well as, student and student. She does not dictate the rules to her students.

"I don't go in and tell them these are the rules".

I tell them "my number one job is to keep you safe and help you learn". We create expectations together and consequences together.

This collaborative process of creating group norms together allows the students to feel ownership of the classroom and feel cared for by the teacher to keep them safe. The study participant considers this another key 
component to building a strong relationship with her students that will enhance the learning environment she is purposefully creating.

3). A system for privileges is collaboratively created that students can earn for working hard. Privileges are based on student interests and also serve as motivators to get school work completed. When asked how she knew which privileges would be effective motivators to entice students to work harder, she replied:

"I just paid attention to them". I noticed this student kept buying a certain privilege so I would prompt him saying "just do 2 sentences and you will get another nickel toward buying the IPad privilege.

Just do 3 sentences, etc.”

This then increases the output for his learning and using the privilege as a motivator to get him to do it.

4). This participant reports that she intentionally studies student behaviors in order to anticipate potential problems either behaviorally or academically so she can be proactive in her response. She gives this example regarding a student who is behaviorally difficult but academically average:

I watch Sam for behaviors that would indicate he is approaching shorting out, then I give him a break. I give him frequent breaks during the course of a lesson because I'm not going to ask him to do something when he is in that state. 
The teacher is able to anticipate and respond effectively to this student because of the purposeful relationship she built with him that is based on observational data she gathers on each student. According to the study participant, this allows the student to continue working productively after each break, and allows the other students to continue working productively because a disruption in the classroom learning environment was averted.

\section{Conclusion}

These findings provide a description of experiences and procedures that guide the development and maintenance of relationships between a teacher and her students. In answer to research question one, four primary categories emerged with supporting elements that were critical components of each category as described in the body of the chapter. The findings to support the answer to question two resulted in four fundamental procedures that the study participant follows to build relationships with her students each year. Chapter Five will provide analysis of these findings and their implications for the learning environment. 


\section{CHAPTER 5}

\section{CONCLUSION}

Stake (1995) writes that the case study report is just one person's perspective and encourages the researcher to include their own personal perspectives in the interpretation (p. 135). In keeping with Stake's guidance, this chapter will include the perspectives and actions of the research participant, as well as my own personal perspective which has influenced my interpretation throughout this study. The findings are supported by the literature that currently exists in the field regarding teacher-student relationships.

\section{Summary of the Study}

This study was conducted as a result of my interest in how teachers' relationships with their students affect the learning environment for those students. It is a topic of interest in the field of education that has been broadly researched for decades (Brophy, 1974;

Evertson, Emmer, \& Brophy, 1980; Grant \& Rothenberg, 1986; Leder, 1987; Baker, 1999; Crosnoe, Johnson, \& Elder, 2004; Hamre \& Pianta, et. al, 2012). 
My purpose for this study was to explore the various aspects of teacher and student relationships as they occur in one particular classroom. The two research questions I wanted to answer were: What specific components of teacher and student interactions are essential to a learning environment? How do teachers describe their process for building relationships with their students? To answer these questions I conducted a single case study at a large elementary school in East Bay of Rhode Island, interviewing and observing a district 'lab classroom' teacher.

The procedures used in conducting this study were thorough and methodical following the recommendations of Stake $(1995,2010)$ and Yin (2003) for case study research. I conducted three interviews and followed them up with classroom observations. The interviews provided opportunities for gaining first hand information and the insight of the study participant. Observations in her classroom were conducted for supporting evidence and clarification. I also reviewed samples of student work for supporting documentation and triangulation. Member checking to insure the accuracy of what I was reporting was the final step in this process. 
The result of this study is a description of experiences and procedures that guide the development and maintenance of relationships between a teacher and her students. Based on the findings, four primary categories emerged with supporting elements that were critical components of each category. These four primary categories represent an interpersonal framework for the learning environment. Constructivist theorists DeVries \& Zan (2005) assert that an interpersonal framework is essential to a child's school experience.

Findings to support the answer to research question two resulted in four fundamental actions the study participant executes to build relationships with her students each year. As Downey (2008) reported, these actions are based on trust, respect, and caring. They serve to promote a sense of cohesiveness in the classroom that Downey found was essential in a learning environment.

\section{Interpretation and Implication of the Study}

Elmore (1996), writing for the Harvard Educational Review, asks the question "How can good educational practice move beyond pockets of excellence to reach a much greater proportion of students and educators?" (p.1). He analyzes how organizations can replicate the 
accomplishments of successful teachers in order for school reform to occur by adopting their successful practices.

Elmore looks at the core of educational practice, in particular, student and teacher relations. Elmore's focus is on changes connected to the way knowledge is constructed that "directly challenge the fundamental relationships among student, teacher, and knowledge" (p. 4). He writes about change as it applies to the teachers' and students' role in constructing knowledge, as well as the role of the classroom structure in effective change in the learning process. As I share my conclusions, I will show evidence to support the importance of the teacher and student relationship as it applies to constructing knowledge. Evidence was also found to support the importance of the structure of the classroom environment as it applies to learning.

Evidence to support Elmore's interest in classroom structure as it affected the learning environment was encapsulated within the findings of Contextual Category 1: Classroom Climate and Contextual Category 2: Classroom Layout with Purposeful Design. In both categories, the structure of the physical space within the participant's classroom and how she formulates the culture of respect and responsibility in her room are purposefully designed to enhance the learning environment and 
learning capacity of her students, affording them the optimum setting for acquiring knowledge. These findings are supported by Dewey (1938) who recommended that teachers use their physical and social surroundings to "extract from them all they have to contribute to building up worthwhile educational experiences" (p. 40). For this study participant, the purposeful design of her classroom gave her the opportunity to utilize her learning environment to its highest and best use.

\section{Finding: Contextual Category 1}

Support for the essential components of Contextual Category 1, of building trust with students, behavior management via consistent routines and procedures and creating consequences for behavior together was found in Hamre, et al. (2012) who studied the impacts of a course designed to enhance the use of effective teacher-student interactions. They determined that Emotional Support and Classroom Organization were core domains of interaction that facilitate a child's developmental progress as a result of their classroom experience (p. 91). My findings in Category 1: Classroom Climate agree with Hamre, et al. who determined the essential components of their category Emotional Support included positive classroom climate and behavior management. 
Support for including the essential components of building a sense of community in the classroom and sense of ownership of classroom comes from Cazden (2001) who states the importance of "each student becoming a significant part of the official learning environment" ( $p$. 131). Cazden believes that a child's intellectual functioning at school is directly related to the quality of the social relationship developed in the classroom environment.

Finding Category 2: Classroom Layout with Purposeful Design When researching predictors of effective teaching practices, Evertson, Emmer, \& Brophy (1980) found that effective teachers had efficient transitions with less transition time between lessons. By creating purposeful traffic patterns and organizing her physical classroom space, the research participant minimized the amount of instructional time students lost transitioning from one work space to another. This study participant's organization of materials also contributed to efficient transition time.

Findings Category 3: Teacher Interaction Behaviors Feedback to Students is considered an important part of the teacher - student relationship dialogue and was found to be an essential 
component of Contextual Category Three: Teacher Interaction

Behaviors.

Evertson, Emmer, \& Brophy (1980) also found feedback to be an important component of teacher interactive behaviors when they studied interactive teaching behaviors in their field-based study of effective teaching practices. As they describe it, feedback was associated with more teacher interaction with students that resulted in the ability to diagnose student misunderstandings and provide corrective explanations. The following vignette occurred during a classroom observation of this case study participant and is supportive evidence of Evertson, Emmer \& Brophy's description of feedback as they reported in their study. It is an example of the teacher using feedback to provide a corrective explanation that resulted in student success.

Vignette: During student work time, the teacher initially reviewed a students' response to a question. She then provided some feedback saying "great job finding two discoveries; now you need some details from the text to explain". The resulting answer that the student provided met the criteria in the standard being assessed due to his incorporation of the feedback 
that the teacher provided. This student was initially giving only a partial answer to the question until the teacher provided feedback allowing the student to fulfill the requirements of the standard being assessed.

This observational vignette also serves as evidence to support Elmore's interest in teacher and student relationships as it applies to their role in constructing knowledge. The interaction between my study participant and her student allowed for the successful construction of knowledge. As the study participant describes the process, "I look at student work and decide what to teach and how to teach it". Her purposeful analysis of student progress allows her to provide the guidance students need to move their learning forward in a constructive way.

Evertson, Emmer, \& Brophy support Use of Praise as an important component of teacher and student interaction. They determined that the use of praise as a means of academic encouragement is significant in the learning environment. My study also supports the use of praise as a significant component to the learning environment. My study participant uses praise in a purposeful manner to guide the academic 
progress of her students toward a specific learning goal. Her praise involves the task at hand and moves the student learning forward.

The inclusion of Personal Discourse as an essential component to Category 3: Teacher Interaction is important to this research study participant as she believes sharing her personal life with her students makes them feel like they are important to her in all aspects of her life; and that this has a positive impact on their learning. There is a considerable amount of research to support the finding that teachers' interpersonal relationship with their students is a significant part of the classroom learning environment (Wubbels, Brekelmans, \& Hoomayers, 1991; Birch \& Ladd, 1998; Pianta, LaParo, Payne, Cox, \& Bradley, 2002; Baker, 2006).

The research study participant's use of humor, a mild tone of voice, and proximity to her students when interacting with them delineates a caring and compassionate learning environment where students feel supported.

\section{Findings Category 4: Delivering Instruction}

Sarason (1999) asserts that the teacher should be constantly looking for ways to engage learners and motivate them so they want to learn. He contends that the teacher should also be able to determine 
when the learner is having difficulty and be able to intercede to mitigate the problem. The essential components to findings category four support Sarason's assertions. This case study research participant uses Scanning and Monitoring, Motivating Students, Student Interests, and Active Listening as methods of "constantly looking for ways to engage the learner and motivate them". The teacher creates learning opportunities that captivate students' interests and lets the students know she is actively engaged in the learning process.

Through Animated Delivery of Instruction the study participant shows enthusiasm while delivering her instruction and delivers enjoyment of the learning process to her students in support of the conclusion that Hamre, et al. (2012) came to.

Fosnot (2005), in support of Active Listening, posits that "the way a teacher listens and talks to children helps them become learners who think critically and deeply" (p. 102). Re-Teaching is an essential component of this study participant's instruction because of her collaborative engagement with her students and her acquired knowledge of their learning styles. This collaborative engagement throughout the learning environment allows a teacher to understand how a particular 
learner acquires knowledge and address the resulting needs of the learner in a more purposeful way (Fosnot, 2005).

Findings for Research Question 2:

As early as 1977, Bruner was contending that one of the purposes of school was to contribute to the social and emotional development of children if he/she wanted to fulfill the function of education (p. 9). McCombs \& Whisler (1997) contend that the need for the teacher to show a personal interest in students is vital to their learning. Marzano (2003) also believes showing interest in students as individuals has a positive impact on their learning. This study participants' interaction with her students has enabled her students to remain engage in the instructional process for longer periods of time, and act on the purposeful guidance and feedback she gives that moves their learning forward. A study of student work samples show how the teacher interaction during a work session increased the student's ability to deepen his/her response to a question resulting in higher learning.

In answer to research question 2, the process used by this study participant to build relationships with her students has four foundational steps. She begins by building trust with her students, frequently engaging with them in conversations about their lives. Following 
Sarason's (1999) counsel that teachers be constantly looking for ways to motivate the learner, this participant also engages in active listening to her students talking with each other to gain insight into potential sources of motivation for the students, and to gather information that she will use to engage her learners through high interest materials and lessons. Support for this practice also comes from Dewey (1938) who believed that the knowledge an educator has of individuals serves to provide students with the opportunity to contribute to something - in this case, their own education.

The second step this study participant engages in is establishing rules and consequences together as an interactional process. This collaboration provides the students with a sense of ownership of the classroom environment being created. Downey (2008) writes that this sense of belonging is critical to a student's success in school.

The third step is to collaboratively create a reward system that allows students to earn privileges for their hard work. This reward system is based on student interest and knowledge gained by the teacher as to what an effective motivator would be. As Crosnoe, Johnson, \& Elder (2004) determined, it serves to keep students committed to the educational process. 
Lastly, this participant deliberately studies student behaviors for more proactive responses to her students in the learning environment. She gathers observational data that she uses to make a strong connection to her students as recommended by Flood, et al. (2003). Flood, et al. contends that this strong connection will result in deep and lasting learning. A contention that this study participant supports as she describes frequent interacting and monitoring of student work to track student learning and insure progress is being made.

As Spiro et al. (1987) describe it, knowledge is acquired through active involvement along with "opportunistic guidance by expert mentors" (p. 614). This study participant, acting as an expert mentor, provides opportunistic guidance to her students through her purposeful classroom design, focused relationship building, and encouraging learning environment.

\section{Summary}

Hamre \& Pianta (2006) recommend that teachers be encouraged to learn about students' lives outside of the classroom as a way to connect with students on a deeper level in order to build a relationship with them. They contend that an emotionally and socially positive school climate contributes to "an atmosphere of cordiality in student- 
teacher relationships" (p.53). Support for Hamre \& Pianta's assertion was substantiated in the findings of the Contextual Categories and in the findings regarding Research Question 2 where the study participant described her process for building relationships with her students. Her 'atmosphere of cordiality' is created by building trust with her students, collaboratively creating class routines and procedures based on respect, active listening, and sharing her own personal stories with her students.

\section{Implications for the Field of Education}

Sarason (1999) asked if there were characteristics of good teachers that could be observed while the teacher interacts with students so the educational community could learn from them. This study provided the opportunity to interview and observe an exemplary teacher yielding a wealth of data for analysis and application to classroom practice. Implications of this case study for the field of education are to serve as further support for the inclusion of teacher-student interpersonal relationship strategies into teacher preparation programs as viable classroom strategies worthy of study. As Darling-Hammond (2006) recommends, "having teacher prep programs that include core knowledge are important, but teachers also need to be prepared to recognize students' diverse ways of learning and develop the ability to 
continually adapt their teaching to effectively respond to the multifaceted nature of the classroom" (p. 6).

I, too, believe that effective teaching has many facets to it that some teachers use quite successfully and that other teachers can learn from. The results of this single case study showed how the purposeful interaction of this teacher created a learning environment that students felt supported in and that guided student learning. The purposeful design of her classroom environment served to enhance the learning and student engagement in her instruction. Students were able to anticipate their next steps in the learning process because this teacher deliberately designed the physical space of her classroom allowing for a continual flow in the instructional process.

Meyer \& Turner (2002) studied emotion in classroom practices and discovered "patterns of interactions among students and teachers for building and supporting classroom contexts associated with positive affect and learning goals" (p. 111). The contextual categories revealed in this case study and the essential components embedded within the categories serve as evidence of effective teacher practices for building a relationship with students that has a positive effect on the learning environment. For evidence of the positive effect this teacher's 
purposeful design had on students, student work samples were reviewed and student responses to the teacher's interaction were observed and recorded.

In addition to Meyer \& Turner's findings, essential components of these contextual categories can also serve as support for Sarason's (1999) edict to motivate learners to experience personal and cognitive growth. I found that this study participant deliberately looked for ways to motive her students by actively listening to them and incorporating their interests into her instruction to promote their continued engagement in the lesson; thereby enhancing cognitive growth.

In theory, many teachers are aware of a cadre of effective practices that educational researchers have been discovering and promoting. However, practical application of these strategies can be an elusive concept without knowing the specific steps to take to implement these strategies. The findings of this case study provided several strategies for practical ways to successfully build a relationship with students that could have an impact on their learning environment. It is an opportunity, as Elmore (1996) recommended, for effective practices to move beyond pockets of excellence into the larger educational realm to reach a greater proportion of teachers and students. 
My recommendations, as a result of this study are to begin incorporating elements of teacher-student interactions into instructional strategies. Using a purposeful design of her classroom and her interactions with her students allowed this study participant to create a learning environment that was meaningful to students as they worked on instructional tasks.

Implications for me, as an administrator, would be to inquire about the design of the classroom and how it enhances the learning environment of the students. I will also incorporate how a teacher interacts with students during instructional, as well as non-instructional time to establish the effect that has on student learning and whether or not it is purposeful.

\section{Limitations of the Study}

The primary concern with conducting case study research has to do with the generalization of the findings. However, Yin (2003) refutes that criticism, writing that the goal of case study research is to "expand on a broader body of knowledge by investigating within a real life context" (p. 10). He contends that this allows for analytic generalizations as opposed to a statistical generalization. 
Limitations to this particular study are due to the scope of the single case that was studied and that the participant is an elementary teacher. Not included in this study is the perception and experiences of other sub-populations of teachers, such as middle and high school teachers. It would be interesting to know if they would concur with the findings of this case study or have any additional insight to add to this conversation. Including their perspective and experience building relationships with their students could provide a broader range of effective strategies to use in the classroom and extend the discussion.

Another limitation is that the study participant, at times, was recalling information that she used months before when the school year began, and as such, could have forgotten some pertinent details of her procedures. Even with this possibility, I believe the information she successfully recalled was valuable and relevant. There was ample evidence to support the conclusion that strategies and procedures discussed and observed were pertinent to the questions under study.

The study may have further limitations in that my role as researcher could have been clouded by my role as a building administrator, albeit not the participant's administrator. Although I tried to mitigate this possibility with my choice of the teacher being 
studied and my detailed explanation of the purpose of the study, it is difficult to know what, if any, effect my position as an administrator had on her. During the interview process and subsequent observations she seemed confident and at ease, providing full access to her classroom for observations and extensive interviews.

Even with these aforementioned limitations, the findings of this case study could provide the field of education with valuable insight into the development of teacher and student relationships that will benefit the learning environment.

\section{Suggestions for Future Research}

As with any investigative undertaking, once you begin your research, other potential subjects to study begin to look interesting. The effort to remain focused on your initial research questions and keep your report streamlined require that you put these other 'interests' on the back burner for the time being. Stake (1995) writes that the most difficult task of the researcher is to "design good research that will direct the looking and thinking enough and not too much" (p. 15).

Meyer \& Turner (2002) recommend future research to find new frameworks exploring interpersonal relationships in classrooms that will 
make future research findings more relevant to teachers and students. They write "comprehensive work that articulates how emotion, motivation, and cognition interact within classroom contexts is needed if understanding learning is to move forward" (p. 112).

As I was investigating the relationships that this one particular elementary teacher created to support her students' learning, I became interested in middle school teachers and high school teachers and what different approaches to building student relationships they used that would affect their learning environment. This would certainly be a consideration for future research as it could potentially identify additional strategies for increasing student learning through teacherstudent interaction. Additional research using a larger group of teachers could be useful as a corroboratory source of further information.

Further research on how teacher relationships with parents affect student learning could also provide valuable information for the field of education. This case study participant spent time building a relationship with her parents so they could be seen as 'partners' in the learning process. While it was a practice of this teacher, it was not the focus of study for my purposes. I do, however, believe it has potential for further 
study as a possible resource for the teacher, as well as the student, in the learning process.

Another suggestion for further research would be to study the practice of providing feedback as this seemed to have a role in the teacher-student interaction process during instruction. Perhaps a more narrow focus on exactly how often feedback needs to occur during the course of the instructional day in order to be effective and the quality of the feedback would be a worthwhile investigation. A recent study of improving teacher feedback during active learning was done by Van den Bergh, Ros, \& Beijaard (2014) as they began investigating the use of feedback during teacher-student interaction that promotes students' metacognition. They recommend further research to identify possible ways to improve feedback in the context of an active learning environment.

\section{Conclusion}

When writing about teacher-student relationships, Marzano \& Marzano (2003) admonish "don't leave relationships to chance” (p. 9). They recommend that by using strategies supported by research, teachers can influence the dynamics of their classrooms and build strong teacher-student relationships that will support student learning (p. 9). 
The particular strategies that my study participant used are well grounded in educational, sociological, and psychological research as described in the literature review.

Through my case study research, I found that the essence of a strong teacher and student relationship revolves around how it affects the teaching and the learning going on in a classroom. Each contextual category that was created as a result of this case study includes specific components of the teacher and student relationship that affect the classroom learning environment in a meaningful way as evidenced by student work samples and student responses to teacher interaction. The actions of this study participant and the resulting findings of this case study serve to support the contention that everyday interactions in the classroom do matter. It is my hope that this study will help promote an emphasis on the value of affective strategies in the classroom that advance the acquisition of knowledge.

This study afforded me the opportunity to gain in-depth knowledge of teacher-student interaction and teacher thinking that has a positive effect on the learning environment. As Sarason (1999) said, "the starting point of all learning is to know the minds and hearts of your learners" (p.110). This case study provided teacher-student relationship 
strategies that, when incorporated into a learning environment, supports the value of knowing the hearts and minds of your students. The purposeful design of a teacher-student interactive learning environment enhances the educational experience for students. 


\section{Marzano Observation Protocol Short Form}

I. - Lesson Segments Involving Routine Events

Design Question N1: What wili do to eftabilsh and poinmunicațe learning goals, trąck studeht: progress, and celobrate suctens?

1. Providing clear learning gouls and sales to measure these goals fe.g. the tescher provides or reminds students a bourt at specifle teaming goail)

$$
\text { a specifle leaming goal) }
$$

2. Tracking student progress (e. E. usinc formontue assassmant the teacher helps studlants chart their indwidual and group progess on a learning goal)

3. Calabrating student sucress fex. the teather helps student acknowdedge shd celebbrite currert status on a learning goal as woll as knowdedge gain)

\section{$3 \frac{8}{2}$}

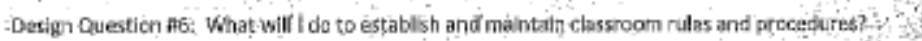

4. Establishing class room rosithes (e.c. the teacher remiects students of a rute of proesdure or establishes a new rulie or
procodure)

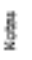

5. Orgenising the physical layeut of tha chesnoom for learning (e.5, the teachar ergarines materlals, traffic patterns, and desplays to enhance learning]
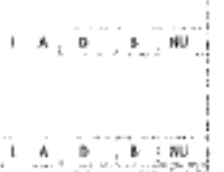

II. Lesson Segments Addressing Content

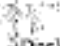

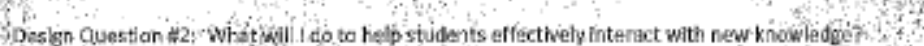

! .....

1. Identifying eftical information (can the teacher provides cues as to which information is important\}.

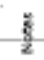

2. Oreanizine students to interact wh new knowlodge fe.p. the teacher organizes students into dyads or trads to discuss small chunks of content)

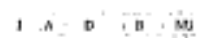

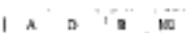

Copyright Robert |. Marzano

Fagre 8 
Desten Quostion wa: What vill i do to establishand iningtain effective relationships with students?

13. Understanding sudents laterests and badkgrounds $(e \cdot E$. the teacher soebs out knowladge aboststudents and uses that knowitadge to angage in Informal, tiend ly dbcusslons whth students)

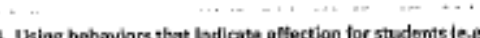
Using behaviors that Ladicate ollection for sudems (e.e. the teadier usas humer and frlendly benter apsropetizoly whith students]

15. Displaying objocthity and eantrol (oe, the teacher behaves in ways that indicate he or she dees not take infractions personaly)

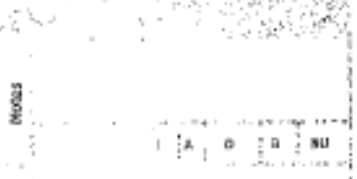

Design Question $* 9$ r" What will i do bo wommunicate hizh expetiations for all students?

16. Demonstrating value and respect for low axpectancy stidents (e.g- the teacher demonstrates the some positive ". affect ve tone wath law axpectancy stadents as with high expectancy students)

17. Askine questions of law expectancy students feg, the teacher asks quastlens of low expectincy students with the same frequency and bevel of diffiality as whith Liph eapoctancy students]

18. Prabing incorrect answers with low expectancy students - - E.g. the teacher ineuires Inte Increct anewers with low high expectancy students]

I $A, D:$ : su , 童 $1,0,0,10$ 
Appendix B

Observation Protocol

Date:

Time:

Name of Observation Site and Person being observed:

Description of Observation Activity:

Physical Setting of Observation:

Observation Notes: (site)

Reflective Notes: (Observer)

Reflective Notes: (Observer)

2.

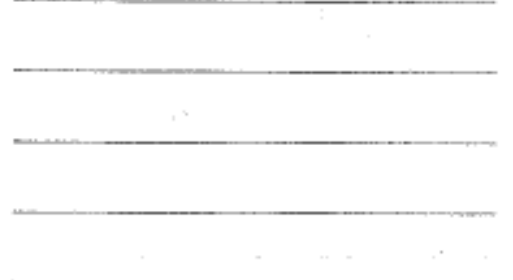

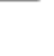


Interview Protocol

Time of Interview:

Date:

Place:

Interviewer:

Interviewee:

Interview Questions: (just a few examples for guidance - not a comprehensive list)

1) How do you create your classroom culture?

Ans.

2) What steps do you take to create your relationship with your students?

Ans.

3) How do you celebrate student success?

Ans.

4) How do you deal with disruptive behavior in your classroom?

Ans.

5) Describe your feelings for your students: 


\section{CONSENT DOCUMENT Rhode Island College}

A Case Study of Student and Teacher Relationships and the Effect on Student Learning

You are being asked to participate in a research study about how teachers interact with their students and whether or not that interaction affects how the student leams. You were selected as a possible participant because you have the distinction of being a lab classroom teacher with a diverse student population. Your classroom has the potential to yield information that can be used in my study. Please read this form and ask any questions that you may have before deciding whether to be in the study.

Patricia Gablinske, a Ph.D. candidate at Rhode Island College, is conducting this study.

\section{Background Information}

The purpose of this research is to describe behaviors and strategies teachers use to interact with their students in the classroom.

\section{Procedures}

If you choose to be a participant in this research, you will be asked to do the following things:

- Participate in 2 or 3 interview sessions that will last approximately 30 to 45 minutes

- Agree to 2 observations, by this researcher, in your classroom setting.

- Allow this researcher access to student feedback, notes, emails/correspondence to parents, and any other form of communication that has the potential to serve as corroborative evidence. All identifying information will be redacted. These documents will be kept strictly confidential and locked in this researcher's home.

\section{Risks of Being in the Study}

The main risks of participating in this research are minimal; meaning that they are about the same as what you would experience in your normal daily activities. Should you experience any risks, please alert the researcher immediately.

\section{Benefits to You}

There are no direct benefits to you for participating in the study.

\section{Voluntary Participation}

Your participation is completely voluntary. It is not required by the district. You can choose not to participate in this research and it will have no effect on your employment. Also, you can change your mind about participating at any time with no negative consequences.

\section{Confidentiality}

The records of this research will be kept private. In any sort of report that might be published, the researcher will not include any information that will make it possible to identify you. Research records will be kept in a secured file, and access will be limited to the researcher. If there are problems with the study, the research records may be viewed by Rhode Island College review board responsible for 
protecting human participants and other government agencies that protect human participants in research. All data will be kept for a minimum of three years, after which it will be destroyed.

\section{Contacts and Ouestions}

The researcher conducting this study is Patricia Gablinske. You may ask any questions you have now. If you have any questions later, you may contact her at pgablinske@gmail.com or 401-316-6564. You may also contact her faculty advisor, Dr. Patricia Cordeiro at pcordeiro@ric.edu.

If you think you were treated unfairly or would like to talk to someone other than the researcher about your rights or safety as a research participant, please contact Dr. Christine Marco, Chair of the Rhode Island College Institutional Review Board at IRB@ric,edu, or by phone at 401-456-8598, or by writing to Dr. Christine Marco, Chair IRB; c/o Department of Psychology, Horace Mann Hall 311; Rhode Island College; 600 Mount Pleasant Avenue; Providence, RI 02908.

You will be given a copy of this form for your records.

\section{Statement of Consent}

I have read and understand the information above, and I agree to participate in the study "A Case Study of Student and Teacher Relationships and the Effect on Student Learning". I understand that my participation is voluntary and can be withdrawn at any time with no negative consequences. I have received answers to the questions I asked, or I will contact the researcher with any future questions that arise. I am at least 18 years of age.

I agree do not agree to be videotaped for this study.

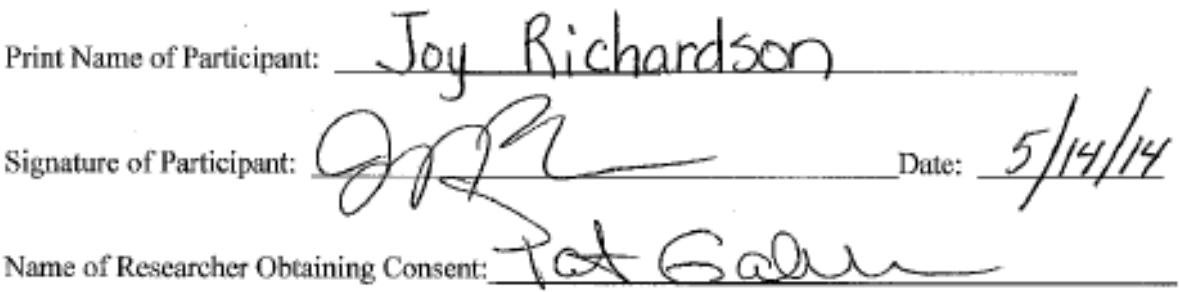


Appendix A

\section{Permission Document}

Rhode Island College/University of Rhode Island

$\mathrm{PhD}$ in Education Program

Rhode Island College

School of Education, Horace Mann Hall

Providence, RI 02908

Title of Project: A Case Study of Student and Teacher Relationships and the Effect on Student Learning

\section{CONSENT FORM TO CONDUCT RESEARCH}

I am a doctoral student in the Ph.D. in Education Joint Program with the University of Rhode Island and Rhode Island College. The reason I am writing to you is to obtain your permission to conduct my dissertation research in the Bristol Warren Regional School District.

My research proposal (attached) is to conduct a single Case Study with one of your elementary school teachers examining the relationship the teacher creates with her students and the potential that has to affect the students' learning. The study will entail the ability to observe in the classroom on 2 or more occasions to gather corroborative evidence of information gleaned from interviews. Interviews with the teacher will occur outside of the school environment and school hours. For the purpose of data triangulation, I will also require your permission to have access to student work samples, correspondence/written notes from the teacher, teacher feedback to students, etc. that could be considered corroborative chain of evidence that learning has occurred. All materials would remain strictly confidential with student identification redacted from all documents.

The study participant will be given an informed consent letter to sign that outlines the specifics of the research and their part in the study. Parents of the students in the classroom will also be given an introductory letter informing them of the study and what my purpose is for being in the classroom as an observer.

This study will pose no risks to the teacher or the students.

The records of this research will be kept private. In any sort of report that might be published, the researcher will not include any information that will make it possible to identify any child or teacher. Research records will be kept in a secured file, and access will be limited to the researcher. If there are problems with the study, the research records may be viewed by Rhode 
Island College review board responsible for protecting human participants and other government agencies that protect human participants in research. All data will be kept for a minimum of three years, after which it will be destroyed.

\section{Statement of Consent}

I have read and understand the information above, and I agree to have the Bristol Warren Regional School district participate in the study of "Student and Teacher Relationships and the Effect on Student Learning".

Print Name: Melider- L.Thies Date: $3 / 24 / 14$

Name of Researcher Obtaining permission: Patricia B. Gablinske 


\section{STATEMENT OF PURPOSE DOCUMENT Rhode Island College}

Dear Participant,

I am a doctoral student in the Ph.D in Education Joint Program with the University of Rhode Island and Rhode Island College. The reason I am contacting you is because I am doing a research study entitled A Case Study of Student and Teacher Relationships and the Effect on Student Learning.

The purpose of this research is to describe behaviors and strategies teachers use to interact with their students in the classroom.

You are being asked to participate in a research study about how teachers interact with their students and whether or not that interaction affects how the student learns. You were selected as a possible participant because you have the distinction of being a lab classroom teacher with a diverse student population. Your classroom has the potential to yield information that can be used in my study.

If you choose to be a participant in this research, you will be asked to do the following things:

- Participate in 2 or 3 interview sessions that will last approximately 30 to 45 minutes

- Agree to 2 observations, by this researcher, in your classroom setting.

- Allow this researcher access to student feedback, notes, emails/correspondenve to parents, and any other form of communication that has the potential to serve as corroborative evidence. $\mathrm{All}$ identifying information will be redacted. These documents will be kept strictly confidential and locked in this researcher's home.

Your participation is completely voluntary. It is not required by the district. You can choose not to participate in this rescarch and it will have no effect on your employment.

If you are willing to participate in this study, please reply to me by email, pgablinskeragmail.com, or call my cell phone (401-316-6564). We can then make an appointment to meet and begin the initial meeting and create a schedule and timeline for our interviews and classroom observations.

I look forward to hearing from you.

Sincerely,

Pat Gablinske

Doctoral Candidate

Rhode Island College 
Appendix G

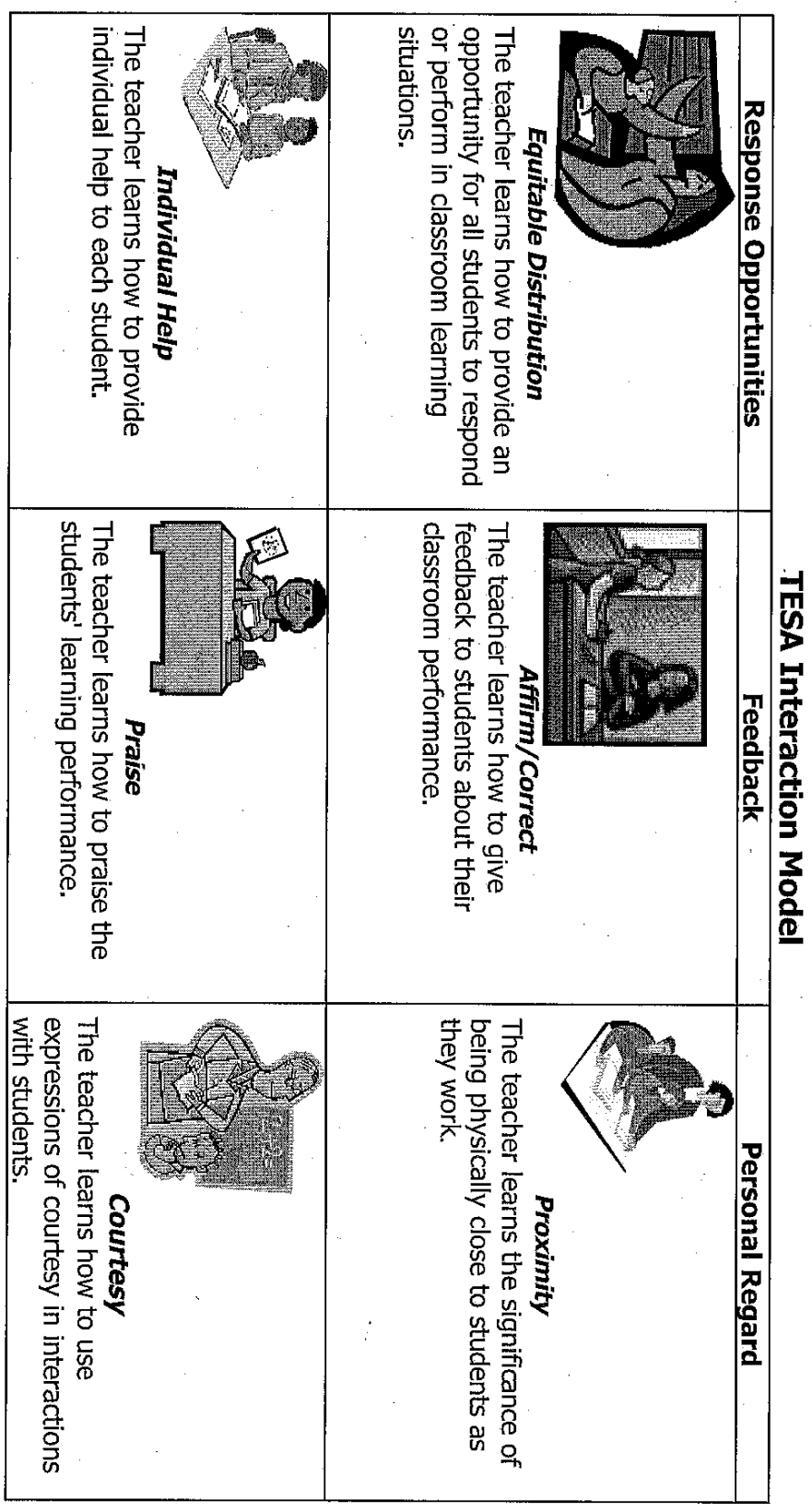


Appendix G

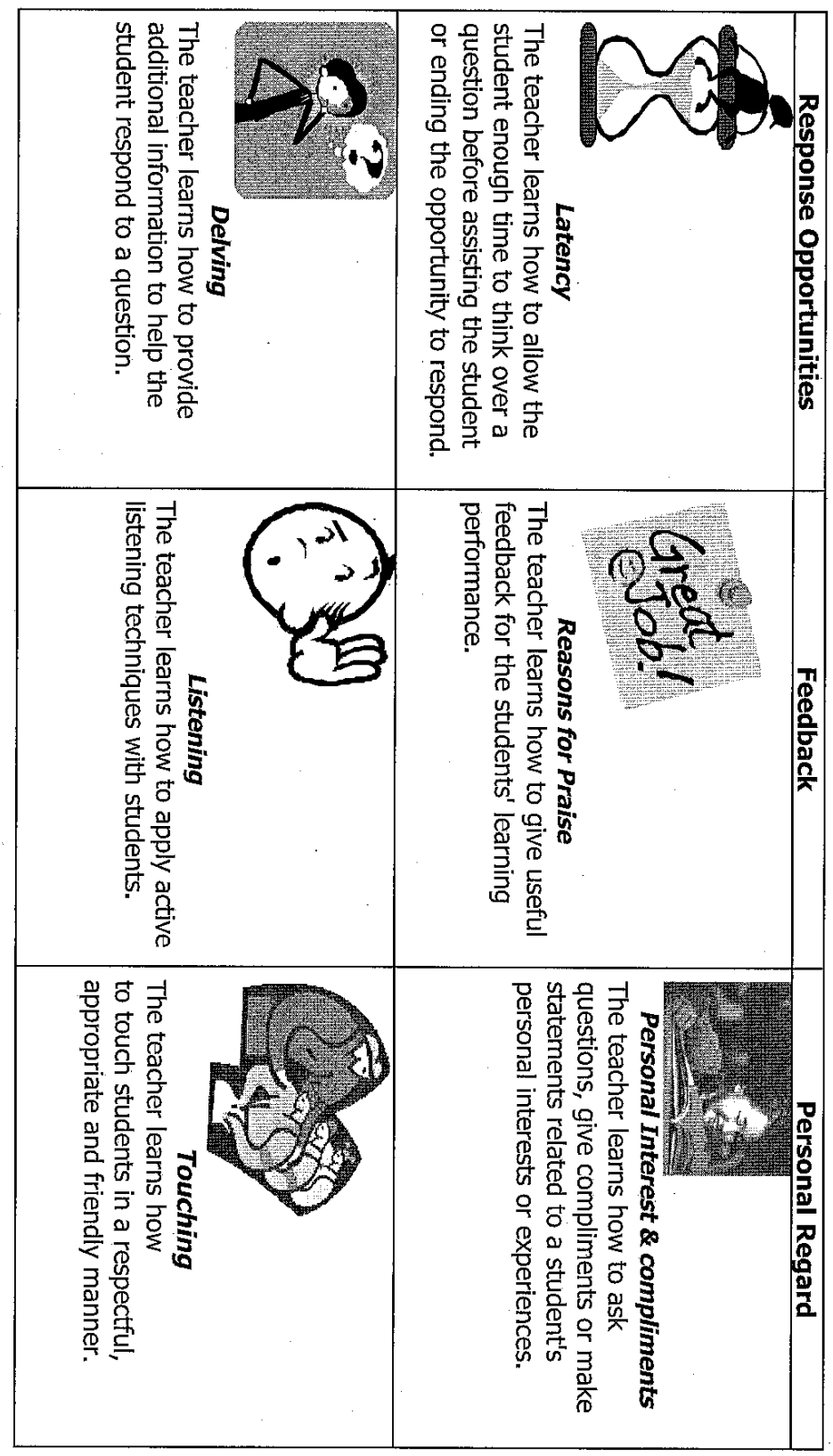


Appendix G

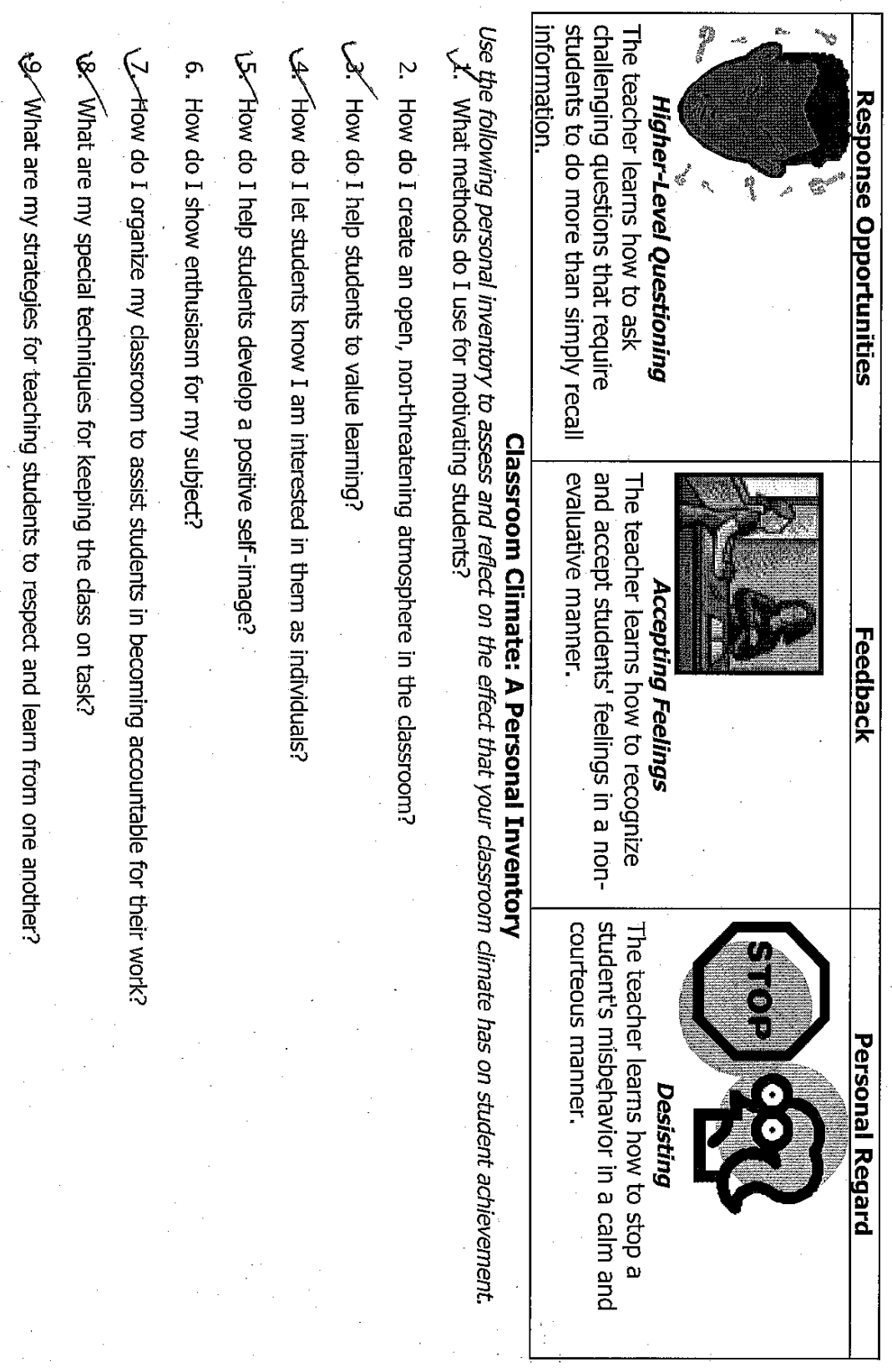




\section{Bibliography}

Askew, S. (2000). Feedback for Learning. Florence, KY, USA:

Routledge, 2000, p 21.

Baker, J.A. (1999). Teacher-Student interaction in urban at-risk

classrooms: differential behavior, relationship quality, and student satisfaction with school. The Elementary School journal, 100:1, 5770.

Baker, J.A. (2006). Contributions of teacher-child relationship to positive school adjustment during elementary school. Journal of School Psychology, 44(3), 211-229.

Bartlett, L., (2005). Dialogue, knowledge, and teacher-student relations: Freirean Pedagogy in theory and practice. Comparative Education Review, 49:3, 344-356.

Birch, S.H., Ladd, G.W. (1998). Children's interpersonal behaviors and the teacher- child relationship. Developmental Psychology, 34(5), 934-946.

Blumer, H., (1969). Symbolic interactionism: perspectives and method. Englewood Cliffs, NJ: Prentice-Hall.

Blumer, H. (1978). Social unrest and collective protest. Studies in symbolic interaction, 1(1978), 1-54. 
Bonk, C. \& Cunningham, D.J. (1998). Searching for learner-centered, constructivist, and socio cultural components of collaborative educational learning tools. Indiana: Indiana University.

Borman, G., \& Overman, L. (2004). Academic resilience in mathematics among poor and minority students. Elementary School Journal, 104, 17-197.

Bracey, G.W. (2009). Identify and Observe Effective Teacher Behaviors. Phi Delta Kappan, 90, 772-773.

Brophy, J.E. (1974). Teacher-student relationships: causes and consequences. NewYork, NY: Holt, Rinehart and Winston.

Brophy, J. E., \& Good, T. L. (1974). Teacher-student relationships: Causes and consequences. Holt, Rinehart \& Winston.

Brophy-Herb, H., Lee, R., Nievar, M. \& Stollak, G. (2007). Preschoolers' social competence Relations to family characteristics, teacher behaviors and classroom climate. Journal of Applied Developmental Psychology, 28(2), 134-148.

Brooks, J. (2006). Strengthening resilience in children and youths: Maximizing opportunities through the schools. Children \& Schools, 28, 2, 69-76. 
Bruner, J. (1977). The process of education. Cambridge, MA: Harvard University Press.

Cazden, C.B. (2001). Classroom discourse the language of teaching and learning. Portsmouth, NH: Heinemann.

Cohen, E. G. (1972). Sociology and the classroom: setting the conditions for teacher- student interaction.Review of Educational Research $42: 4,441-452$.

Creswell, J.W. (1998). Qualitative inquiry and research design: Choosing among five traditions. Thousand Oaks, CA: Sage.

Creswell, J.W. (2013). Qualitative inquiry \& research design: Choosing among five approaches. Thousand Oaks, CA: Sage.

Crosnoe, R., Johnson, M.K., \& Elder, G.H. (2004). Intergenerational bonding in school the behavioral and contextual correlates of student teacher relationships. Sociology Of Education, 77:1, 60-81.

Curby, T., LoCasale-Crouch, J., Konold, T., Pianta, R., Howes, C., Burchinal, M., ... Oscar, B. (2009). The relations of observed prek classroom quality profiles to children's achievement and social competence. Early Education \& Development, 20(2), 346-372. 
Danielson, C. (2007). Enhancing professional practice: A framework for teaching (2nd ed.). Alexandria, VA: Association for Supervision and Curriculum Development.

Darling-Hammond, L. (2006). Constructing $21^{\text {st }}$ - Century teacher education. Journal of Teacher Education, 57, 1-15.

Darling-Hammond, L. (1996) What matters most: A competent teacher for every child. Phi Delta Kappan, 48:3, 193-200.

Darling-Hammond, L., Youngs, P. (2002). Defining “highly qualified teachers": what does "scientifically-based research" actually tell us? Educational Researcher, 31:9, 13-25.

Darling-Hammond, L., \& Sykes, G. (2003). Wanted: a national teacher supply policy for Education: the right way to meet the "highly qualified teacher" challenge. Education Policy Analysis Archives, $11: 33,1-55$.

Deyhle, D. L., Hess, GA jr. \& LeCompte, MD (1992). Approaching Ethical Issues for Qualitative Researchers in Education.

DeVries, R., Zan, B. (2005). In Fosnot, C. (ed.). Constructivism: Theory, Perspectives and Practice. New York, NY: Teachers College Press.

Dewey, J.(1938). Experience and Education. New York, NY: Touchstone. 
Dickinson, D., \& Brady, J. (2006). Toward effective support for language and literacy through professional development. In M. Zaslow \& L. Martinex-Beck (Eds.), Critical issues in early childhood professional development (pp. 141-170). Baltimore, MD: Brookes Publishing.

Downey, J.A. (2008). Recommendations for fostering educational resilience in the Classroom. Preventing School Failure, 53, 56-63.

Dunn, T. (2004). Enhancing mathematics teaching for at-risk students: Influences of a teaching experience in alternative high school. Journal of Instructional Psychology,31(1), 46-52.

Eccles, J.S., \& Wigfield, A. (2002). Motivational Beliefs, Values, and Goals. Annual Review Psychology, 53:109-32.

Elmore, R. F. (1996). Getting to scale with good educational practice. Harvard Educational Review.

Evertson,C. M, Emmer, E.T., \& Brophy, J.E., (1980). Predictors of effective teaching in junior high mathematics classrooms. Journal for Research in Mathematics Education, 11(3), 167-178.

Flood, J., Lapp, D., Squires, J.R., \& Jensen, J.M. (2003). Handbook of research on teaching the English language arts. Mahwah,NJ: Lawrence Erlbaum Associates. 
Fosnot, C.T. (2005). Contructivism: theory, perspectives and practice. New York: Teachers College Press.

Glaser, B., \& Strauss, A. (1967). The discovery of grounded theory. New York, NY: Aldine De Gruyter.

Good, T.L., Biddle, B.J., \& Brophy, J.E. (1976). The effects of teaching: An optimistic note. The Elementary School Journal, 76:6, 365-372.

Grant, L. \& Rothenberg, J. (1986). The social enhancement of ability differences:Teacher-student interactions in first and second grade reading groups. The Elementary School Journal, 87:1, 29-49.

Guo, Y., Piasta, S. B., Justice, L.M., \& Kaderavek, J.N. (2010). Relations among preschool teachers' self-efficacy, classroom quality, and children's language and literature gains. Teaching and Teacher Education, 26(4), 1094-1103.

Hallinan, M.T. (2008). Teacher influences on students' attachment to school. Sociology of Education, 81(3), 271-283.

Hamre, B.K., Pianta, R.C., Burchinal, M., Field, S, Crouch, J.L., Downer, J. T., Howes, C., LaParo, K., Little, C.S. (2012). A course on effective teacher-child interactions: Effects on teacher beliefs, knowledge, and observed practice. American Educational Research Journal, 49:1, 88-123. 
Hamre, B. K., \& Pianta, R. C. (2006). Student-Teacher Relationships.

Hamre, B. K., \& Pianta, R. C. (2001). Early teacher-child relationships and the trajectory of children's school outcomes through eighth grade. Child development, 72(2), 625-638.

Horvat, E., Weininger, E., \& Laureau, A. (2003). From social ties to social capital: Class Differences in the relations between schools and parents network. American Educational Research Journal, 402(2), 319-351.

Howes, C., Burchinal, M., Pianta, R., Bryant, D., Early, D., Clifford, R., \& Oscar, B. (2008). Ready to learn? Children's pre-academic achievement in pre-kindergarten programs. Early Childhood Research Quarterly, 23(1), 27-50.

Jackson, B., Larzelere, R., St. Clair, L., Corr, M., Fichter, C., \& Egertson, H. (2006). The impact of "HeadsUp! Reading" on early childhood educators' literacy practices and pre- school children's literacy skills. Early Childhood Research Quarterly, 21, 213-226.

Jackson, P.W., (1968). Life in classrooms. New York, NY: Holt, Rinehart \& Winston.

Langer, E.J., (1997). The power of mindful learning. Reading, MA: Perseus Books. 
LaParo, K.M, Pianta, R.C., Stuhlman, M. (2004). The classroom assessment scoring system: Findings from the prekindergarten year. The Elementary School Journal, 104:5, 410-426.

Leder, G.C. (1987). Teacher Student Interaction: a case study. Educational Studies in Mathematics, 18, 255-271.

Little, J.W. (2003). Inside teacher community: representations of classroom practice. Teachers College Record. 105 (6). 914-945.

Mann, H., (1840). In Cremin, L.A. (Ed.). 1957. The Republic and the School: Horace Mann on the Education of Free Men. New York, NY: Teachers College Press.

Martin, J., Veldman, D.J., \& Anderson, L.M. (1980). Within-class relationships between Student achievement and teacher behaviors. American Educational Research Journal, 17:4, 479-490.

Marzano, R. J. \& Marzano, J.S. (2003). Building Classroom Relationships. Educational Leadership, 61:1, 6-13.

Marzano, R.J., Marzano, J.S. \& Pickering, D. (2003). Classroom management that works: research-based strategies for every teacher. Alexandria,VA: Association For Supervision and Curriculum Development. 
Marzano, R.J.,(2003). What works in schools translating research into action. Alexandria, VA: Association for Supervision and Curriculum Development.

Mashburn, A.J., Pianta, R. C., Hamre, B. K., Downer, J.T., Barbarin, O., Bryant, D., ... Howes, C. (2008). Measures of classroom quality in prekindergarten and children's development of academic, language, and social skills. Child Development, 79(3), 732-749.

McCartney, K., Dearing, E., Taylor, B., \& Bub, K. (2007). Quality child care supports the achievement of low-income children direct and in-direct pathways through care giving and the home environment. Journal of Applied Developmental Psychology, 28(5-6), 411-426.

McCombs, B. L., \& Whisler, J. S. (1997). The Learner-Centered Classroom and School: Strategies for Increasing Student Motivation and Achievement. The Jossey-Bass Education Series. Jossey-Bass Inc., Publishers, 350 Sansome St., San Francisco, CA 94104.

Meyer, D.K., \& Turner, J.C. (2002). Discovering emotion in classroom motivation research. Educational Psychologist, 37(2),107-114. 
Mohrman, S., Tenkasi, R., \& Mohrman, A. (2003). The role of networks in fundamental organizational change. Journal of Applied Behavioral Science, 39(3), 301-323.

Moolenaar, N., Daly, A.J., \& Sleegers, P. (2009). Ties with potential: Social network structure and innovation in Dutch schools. Teachers College Record.

Murdoch, K. (2008). Creating a learner-centred primary classroom: Learner centered strategic learning. London; New York: Routledge.

O’Connor, E.E., Dearing, E., \& Collins, B.A. (2011). Teacher-child relationship and behavior problem trajectories in elementary school. American Educational Research Journal, 48:1,120-162.

Patton, M. Q. (2002). Qualitative Research \& Evaluation Methods. Thousand Oaks, CA: Sage.

Penuel, W.R., Riel, M.R., Krause, A., \& Frank, K.A. (2009). Analyzing teachers' professional interactions in a school as social capital: A social network approach. Teachers College Record, 111(1), 124163.

Piaget, J. \& Inhelder, B. (2000). The psychology of the child. New York, NY: Basic. 
Pianta, R. C. (1999). Enhancing relationships between children and teachers. American Psychological Association.

Pianta, R. C., Barnett, W. S., Burchinal, M., \& Thornburg, K. R. (2009). The Effects of Preschool Education What We Know, How Public Policy Is or Is Not Aligned With the Evidence Base, and What We Need to Know. Psychological Science in the Public Interest, 10(2), 49-88.

Pianta, R.C., La Paro, K., Payne, C., Cox, M. \& Bradley, R. (2002). The relation of kindergarten classroom environment to teacher, family, and school characteristics and child outcomes. Elementary School Journal, 102(3), 225-238.

Ravitch, D. (2010). The death and life of the great American school system: how testing and choice are undermining education. New York: Basic Books.

Riggs, E.G. (2009). Strategies that promote student engagement: unleashing the desire to learn. Thousand Oaks, CA: Corwin Press. Rothstein, R. (2009). What's wrong with accountability by the numbers? American Educator, 20-32. 
Rothstein, R., Jacobsen, R., \& Wilder, T. (2008). Grading education: Getting accountability right. Washington: Economic Policy Institute. Teachers College Press. NY

Rubin, H.J.,\& Rubin, I.S. (2005). Qualitative interviewing: The art of hearing data. Thousand Oaks, CA: Sage.

Sarason, S. B. (1999). Teaching as a performing art. Teachers College Press. NY

Skinner, E., Belmont, M. (1993). Motivation in the classroom: Reciprocal effects of teacher behavior and student engagement across the school year. Journal of Educational Psychology. 85 (4) 571-581.

Smith, H.A. (2006). Signs of the Expert Teacher. In Teaching Adolescents: educational psychology as a science of signs (302312). Toronto: University of Toronto Press.

Spiro, R. J. (1988). Cognitive Flexibility Theory: Advanced Knowledge Acquisition in Ill-Structured Domains. Technical Report No. 441.

Stake, R. E. (2010). Qualitative Research: studying how things work. New York: Guilford Press.

Stake, R. E. (1995). The art of case study research. Sage. Thousand Oaks, CA. 
Sullo, R.A. (2007). Activating the desire to learn. Alexandria, VA: Association for Supervision and Curriculum Development.

Thompson, R.H., White, K.R. \& Morgan, D.P. (1982). Teacher-student interaction patterns in classrooms with mainstreamed mildly handicapped students. American Educational Research Journal, $19: 2,220-236$.

Van den Bergh, L., Ros, A., \& Beijaard, D., (2014). Improving teacher feedback during active learning: effects of a professional development program. American Educational Research Journal, 51(4), 772-809.

Vygotsky, L.S. (1978). Mind in Society. Cambridge, MA: Harvard University Press.

Wise, A., Darling-Hammond, L., McLaughlin, M., \& Bernstein, H. (1984). Teacher evaluation: A study of effective practices. Santa Monica, CA: Rand.

Wubbels, T., \& Brekelmans, M. (2005). Two decades of research on teacher-student relationships in class. International Journal of Educational Research,43(1), 6-24.

Yin, R. K. (1994). Case study: design and methods. Newbury Park, Sage Publications. 
Yin, R. K. (2003) Case study research designs and methods ( $3^{\text {rd }}$ ed.). Thousand Oaks, CA: Sage.

Yin, R. K. (2009) Case study research designs and methods (4 ${ }^{\text {th }}$ ed.). Thousand Oaks, CA: Sage 